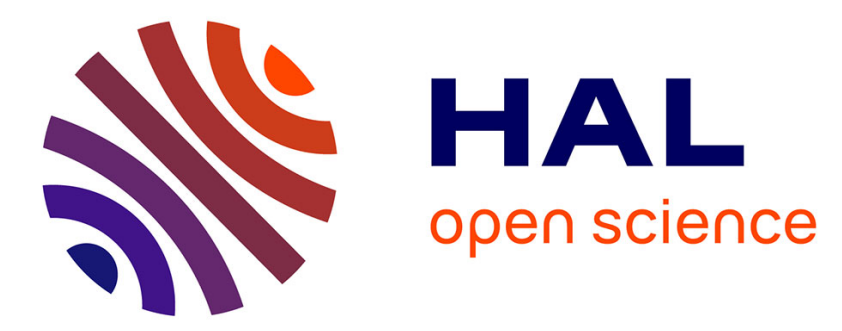

\title{
Exploring pyrolysis and oxidation chemistry of o-xylene at various pressures with special concerns on PAH formation
}

\author{
Wenhao Yuan, Long Zhao, Sandro Gaïl, Jiuzhong Yang, Yuyang Li, Fei Qi, \\ Philippe Dagaut
}

\section{To cite this version:}

Wenhao Yuan, Long Zhao, Sandro Gaïl, Jiuzhong Yang, Yuyang Li, et al.. Exploring pyrolysis and oxidation chemistry of o-xylene at various pressures with special concerns on PAH formation. Combustion and Flame, 2021, 228, pp.351-363. 10.1016/j.combustflame.2021.02.010 . hal-03216710

\author{
HAL Id: hal-03216710 \\ https://hal.science/hal-03216710
}

Submitted on 4 May 2021

HAL is a multi-disciplinary open access archive for the deposit and dissemination of scientific research documents, whether they are published or not. The documents may come from teaching and research institutions in France or abroad, or from public or private research centers.
L'archive ouverte pluridisciplinaire $\mathbf{H A L}$, est destinée au dépôt et à la diffusion de documents scientifiques de niveau recherche, publiés ou non, émanant des établissements d'enseignement et de recherche français ou étrangers, des laboratoires publics ou privés.

$$
\text { Copyright }
$$




\title{
Exploring pyrolysis and oxidation chemistry of $o$-xylene at various pressures with
}

\section{special concerns on PAH formation}

\author{
Wenhao Yuan ${ }^{1}$, Long Zhao ${ }^{2}$, Sandro Gaïl ${ }^{3}$, Jiuzhong Yang ${ }^{2}$, Yuyang Li $^{1,{ }^{*}}$, Fei Qi ${ }^{1}$, Philippe Dagaut ${ }^{3},{ }^{*}$ \\ 1. Key Laboratory for Power Machinery and Engineering of MOE, School of Mechanical \\ Engineering, Shanghai Jiao Tong University, Shanghai 200240, P. R. China \\ 2. National Synchrotron Radiation Laboratory, University of Science and Technology of China, \\ Hefei, Anhui 230029, P. R. China \\ 3. C.N.R.S.-I.N.S.I.S., Institut de Combustion, Aérothermique, Réactivité et Environnement, 1C, \\ Avenue de la Recherche Scientifique, 45071 Orléans Cedex 2, France
}

\begin{abstract}
This work reports an experimental and kinetic modelling investigation on flow reactor pyrolysis and jet-stirred reactor oxidation of $o$-xylene. The flow reactor pyrolysis experiments were conducted over $1050-1600 \mathrm{~K}$ at 0.04 and $1.0 \mathrm{~atm}$. Key products related to fuel decomposition such as $o$-xylyl radical, $o$-xylylene, benzocyclobutene and styrene, as well as polycyclic aromatic hydrocarbons (PAHs), were detected by using synchrotron vacuum ultraviolet photoionization mass spectrometry. The jet-stirred reactor oxidation experiments were performed at $10 \mathrm{~atm}, 800-1200 \mathrm{~K}$, a residence time of $0.5 \mathrm{~s}$ and equivalence ratios of $0.5,1.0$ and 2.0. Speciation were conducted by using gas chromatography and Fourier transform infrared spectrometry. A kinetic model of $o$-xylene was developed from our previous models of aromatic fuels and validated against both present data and experimental data in literature. Styrene is observed as the dominant product in the pyrolysis of $o$ xylene and it is mainly produced from the isomerization of $o$-xylylene directly or via benzocyclobutene as an intermediate species. C9 PAHs (indenyl, indene and indane), phenanthrene and its methyl derivatives were observed as the abundantly produced bicyclic and tricyclic PAHs. The main formation pathways of bicyclic and tricyclic PAHs are found to be different at low and atmospheric pressures, depending on the major precursors produced. Particularly, the self-combination reactions of $o$-xylyl and the addition reaction of $o$-xylyl with benzyl and subsequent stepwise $\mathrm{H}-$ loss/cyclization reactions are found to be the main sources of methylphenanthrene and dimethylphenanthrene. In the JSR oxidation of $o$-xylene, toluene and benzene were observed as the abundantly produced aromatic products, while $o$-methylbenzaldehyde was among the most abundantly produced oxygenated aromatics. Modelling analysis reveals that $o$-xylyl radical is also the dominant fuel consumption product. Its consumption mainly proceeds through the oxidation by $\mathrm{HO}_{2}$ and finally produces $o$ methylbenzaldehyde. Further decomposition reactions of $o$-methylbenzaldehyde contribute to the formation of other major oxygenated aromatics such as cresol and benzofuran. Indene and naphthalene were also observed in the oxidation of $o$-xylene, which are mainly produced from the stepwise $\mathrm{H}$ loss/cyclization reaction sequence of $o$-methylethylbenzene and decomposition of dibenzofuran, respectively.
\end{abstract}

Keywords: $o$-xylene; flow reactor pyrolysis; jet-stirred reactor oxidation; kinetic model; PAH formation

\section{Introduction}

Xylene isomers are important aromatic components in gasoline and are commonly used as octane boosters to enhance anti-knock properties of gasoline due to their high octane numbers [1]. Despite the advantages, the combustion of xylenes can readily produce polycyclic aromatic hydrocarbons

\footnotetext{
*Corresponding authors. E-mail: yuygli@s,jtu.edu.cn (YL), dagaut@enrs-orleans.fr (PD).
} 
(PAHs) and soot [2], which are among major combustion pollutants. A better understanding of the fuel decomposition and PAH formation chemistry of xylenes can benefit the understanding of combustion chemistry of aromatic fuels and help develop kinetic models of transportation surrogate fuels. Among the three xylene isomers, the combustion chemistry of $o$-xylene is of special interest because the two adjacent methyl groups provide the possibility of intramolecular $\mathrm{H}$-transfer and consequently $o$-xylene manifests greater reactivity than other two isomers [3].

Previous studies of $o$-xylene combustion either focused on the speciation in the oxidation or flames at low-to-atmospheric pressures [4-8], or were dedicated on the measurements of global combustion parameters [5, 9-15]. Among the speciation experiments, Emdee et al. [4] investigated the flow reactor oxidation of $o$-xylene at $1 \mathrm{~atm}$ and $1150 \mathrm{~K}$. The mole fractions of some major products were measured using gas chromatography (GC). Gail et al. [5] investigated the oxidation of $o$-xylene in a jet-stirred reactor (JSR) at 1 atm using GC. Li et al. [6] and Zhao et al. [7] investigated laminar premixed flames of $o$-xylene at $0.04 \mathrm{~atm}$ and equivalence ratios $(\phi)$ from 0.75 to $1.79 \mathrm{using}$ synchrotron vacuum ultraviolet photoionization mass spectrometry (SVUV-PIMS). Wang et al. [8] measured the $\mathrm{OH}$ time histories in the shock tube oxidation of $o$-xylene at pressures around $1.2 \mathrm{~atm}$ and temperatures from 1513 to $1877 \mathrm{~K}$ using laser absorption spectroscopy. In regard to the global combustion parameter measurements, Roubaud et al. [9, 10] measured the ignition delay times of $o$-xylene in a rapid compression machine at pressures above $14 \mathrm{~atm}$ and temperatures of 600-900 K. Gaïl et al. [5] measured the ignition delay times of $o$-xylene at $1 \mathrm{~atm}$, temperatures of $1400-1830 \mathrm{~K}$ and equivalence ratios from 0.5 to 2.0. Battin-Leclerc et al. [11] measured the ignition delay times of $o$-xylene at pressures from 6.7 to 9 atm, temperatures from 1330 to $1800 \mathrm{~K}$ and equivalence ratios from 0.5 to 2.0. Shen and Oehlschlaeger [12] measured the ignition delay times in a shock tube at pressures from 10 to $40 \mathrm{~atm}$, temperatures from 941 to $1408 \mathrm{~K}$ and equivalence ratios from 0.5 to 1.0. Recently, Kukkadapu et al. [15] measured the ignition delay times of $o$-xylene in a rapid compression machine $(\mathrm{RCM})$ at pressures of 25-45 atm, temperatures of 850-1000 $\mathrm{K}$ and equivalence ratios of $0.5-1.0$. The laminar flame speeds of $o$-xylene were also measured by $\mathrm{Ji}$ et al. [13] at the initial pressure $\left(\mathrm{P}_{\mathrm{u}}\right)$ of 1 atm and initial temperature $\left(\mathrm{T}_{\mathrm{u}}\right)$ of $353 \mathrm{~K}$ and by Han et al. [14] at $\mathrm{P}_{\mathrm{u}}=1-2 \mathrm{~atm}$ and $\mathrm{T}_{\mathrm{u}}=353 \mathrm{~K}$. Furthermore, Han et al. [14] also measured the ignition temperatures of $o$-xylene at 1-3 atm using a counterflow ignition apparatus.

Based on above experimental results, several kinetic models for $o$-xylene oxidation were developed by validating one or two sets of experimental data [5, 11, 15]. Specifically, Gaïl et al. [5] developed a detailed kinetic model by validating their measured JSR oxidation data at $1 \mathrm{~atm}$. BattinLeclerc et al. [11] developed a detailed kinetic model and validated against their measured ignition delay time data as well as the flow reactor oxidation data from Emdee et al. [4]. Kukkadapu et al. [15] developed a detailed kinetic model by validating their measured ignition delay time data, as well as the flow reactor oxidation data from Emdee et al. [4], JSR oxidation data from Gail et al. [5] and laminar flame speed data from Ji et al. [13]. It is recognized that there is no speciation investigation on the pyrolysis of $o$-xylene, the speciation experiments on $o$-xylene oxidation at high pressure are insufficient, and a kinetic model of $o$-xylene combustion which is widely validated against available experimental data and covers both fuel decomposition and PAH formation chemistry is still lacking. Thus, more experimental and modeling efforts will be needed to better understand the combustion chemistry of $o$-xylene.

This work aims to perform a speciation investigation on the pyrolysis and oxidation of $o$-xylene under extended experimental conditions compared with previous studies. The flow reactor pyrolysis experiments of $o$-xylene were performed at pressures of 0.04 and 1 atm with SVUV-PIMS, while the JSR oxidation experiments of $o$-xylene were conducted at 10 atm and equivalence ratios of $0.5,1.0$ and 2.0 with GC and Fourier transform infrared spectroscopy (FTIR). Furthermore, a kinetic model 
was developed to provide new insights into the fuel decomposition and PAH formation chemistry of $o$-xylene. The model was also validated against the available speciation data and global parameters reported in previous work.

\section{Experimental methods}

\subsection{Flow reactor pyrolysis}

The flow reactor pyrolysis experiments were performed at the National Synchrotron Radiation Laboratory. Detailed introduction to the beamline and the flow reactor apparatus have been introduced elsewhere [16-19]. $o$-Xylene (purchased from Sinopharm Chemical Reagent Limited Co., Shanghai, China, with purity $\geqslant 99 \%$ ) was gasified in a home-made vaporizer. After vaporization, the gas mixture of $o$-xylene (1\%) and argon (99\%) with a total flow rate of 1000 standard cubic centimeters per minute ( $\mathrm{sccm}$ ) was fed into a flow tube with $22 \mathrm{~cm}$ length. The flow tube was made of $\alpha$-alumina to reduce wall catalytic effects $[20,21]$. A small inner diameter $(0.7 \mathrm{~cm})$ was used to ensure strong radial diffusion effects and achieve adequately homogeneous reaction circumstance [22-24]. In this work, the pressures were maintained at 0.04 and $1 \mathrm{~atm}$. Temperature profiles along the flow reactor centerline were measured using an S-type thermocouple [16]. Methodologies for intermediate identification and mole fraction evaluation were also reported in detail previously [25, 26]. With SVUV-PIMS, stable intermediates, isomers, radicals and PAHs were detected in this work. The uncertainties of obtained mole fractions mainly come from the uncertainties of photoionization cross sections (PICSs), which are estimated to be within $\pm 25 \%$ for pyrolysis products with known PICSs and a factor of 2 for those with estimated PICSs. The PICSs used in this work are provided in Table S1 in the Supplementary Material (SMM) \#1.

\subsection{JSR oxidation}

The JSR oxidation experiments were performed at C.N.R.S.-I.N.S.I.S. Table 1 lists the detailed experimental conditions. The JSR used in this work and the experimental procedure are similar to those used earlier [27]. It consists of a small fused silica sphere of $40 \mathrm{~mm}$ outer diameter $\left(30.5 \mathrm{~cm}^{3}\right)$. Four nozzles of $1 \mathrm{~mm}$ inner diameter were mounted in the sphere to feed the gases and achieve stirring. Two regulated heating wires of ca. $1.5 \mathrm{~kW}$ maintained the temperature of the reactor at the desired working temperature. Good thermal homogeneity along the whole vertical axis of the reactor (gradients of ca. $1 \mathrm{~K} / \mathrm{cm})$ was observed for each experiment by thermocouple $(0.16 \mathrm{~mm}$ chromelalumel) measurements (typical change $\leqslant 5 \mathrm{~K}$ ). A high-pressure liquid chromatography pump (Hewlett Packard 1100) was used to deliver $o$-xylene mixture to an atomizer-vaporizer. A high degree of nitrogen dilution ( $0.1 \%$ volume of $o$-xylene) was used in order to reduce temperature gradients in the reactor caused by the oxidation heat release. All the gases were preheated before injection to minimize temperature gradients inside the reactor. The reacting mixtures were sampled by means of a fused silica low-pressure sonic probe. The reactants, products and stable intermediates were analyzed online by FTIR (10 m path length, $200 \mathrm{mBar}$, resolution of $0.5 \mathrm{~cm}^{-1}$ ), GC-MS (Varian Quadrupole V1200)-flame ionization detector (FID) and off-line after collection and storage in 1 L Pyrex bulbs. Off-line analyses were performed using GC equipped with capillary columns (DB-5ms, $\mathrm{Al}_{2} \mathrm{O}_{3}-\mathrm{KCl}$, Poraplot U and Carboplot-P7), a thermal conductivity detector (TCD) and an FID. In this work, the experiments were performed at 10 atm and $\phi=0.5,1.0$ and 2.0, while the residence time $(\tau)$ was kept at a constant value of $0.5 \mathrm{~s}$ by changing the flow rate of reactants. The uncertainties of the species mole fractions are estimated to be around $\pm 15 \%$ [28]. The experimental data of both flow reactor pyrolysis and JSR oxidation can be found in SMM \#2.

Table 1 Conditions of the JSR oxidation of $o$-xylene.

\begin{tabular}{llllll}
\hline$\phi$ & $P / \mathrm{atm}$ & Fuel $/ \%$ & $\mathrm{O}_{2} / \%$ & $\mathrm{~N}_{2} / \%$ & $\tau / \mathrm{s}$ \\
\hline
\end{tabular}




\begin{tabular}{llllll}
\hline 0.50 & 10 & 0.1 & 2.100 & 97.800 & 0.5 \\
1.00 & 10 & 0.1 & 1.050 & 98.850 & 0.5 \\
2.00 & 10 & 0.1 & 0.525 & 99.375 & 0.5 \\
\hline
\end{tabular}

\section{Kinetic model development}

A detailed kinetic model of $o$-xylene consisting of 415 species and 2726 reactions was developed by extending our recent kinetic models of aromatic fuels [29-32]. For most of the reactions in the submechanism of $o$-xylene, their rate constants lack experimental and theoretical investigations. In the present model, the sub-mechanism of $o$-xylene was constructed by mainly referring to the submechanism of toluene [30]. Table S2 in SMM \#1 lists the selected reactions in the sub-mechanism of $o$-xylene. Some key reactions will be discussed in detail below.

The rate constants for the $\mathrm{C}-\mathrm{H}$ bond dissociation, $\mathrm{H}$-abstraction and ipso-substitution reactions of $o$-xylene were analogous to those for similar reactions of toluene [30]. Special attentions were paid on the decomposition reactions of $o$-xylyl radical. Based on available theoretical [3, 33-35] and experimental [36-39] progresses and analogy to benzyl reactions, detailed $o$-xylyl decomposition pathways were incorporated in the present model. The pathways include its decomposition to $O$ xylylene and $\mathrm{H}$, decomposition to fulvenallene and methyl, 2-methylfulvenallene and $\mathrm{H}, 1,3-$ cyclopentadiene and methylcyclopentadienyl via ring-rearrangement reactions, decomposition to benzocyclobutene via ring-closure reaction, decomposition to benzyl via $\mathrm{H}$-attack reaction and isomerization to $m$-xylyl or dimethylphenyl. As a resonantly stabilized radical, $o$-xylyl has the possibility to proceed self-combination or addition reactions with other resonantly stabilized radicals such as benzyl, phenyl or abundantly produced radicals such as methyl. Rate constants of these reactions were referred to similar reactions of benzyl. Pachner et al. [33] suggested that $o$-xylylene can isomerize to styrene or benzocyclobutene and the latter is more energetically favoured. Benzocyclobutene can also isomerize to styrene. Furthermore, the reactions of $o$-xylyl with $\mathrm{HO}_{2}, \mathrm{O}_{2}$, $\mathrm{O}$ and $\mathrm{OH}$ to produce $o$-methylbenzoxyl, $o$-methylbenzaldehyde and $o$-methylbenzalcohol, together with the decomposition reactions of the three products, were incorporated in the present model with the rate constants referred to the similar reactions of benzyl.

The thermochemical properties of the species in the sub-mechanism of $o$-xylene were either taken from the work of Kukkadapu et al. [15] or estimated using the THERM software [40]. Table S3 in SMM \#1 lists the species with estimated thermodynamic properties. Besides the new data in this work, the model was also validated against the available speciation data in JSR oxidation at atmospheric pressure [5], shock tube oxidation [8], low pressure laminar premixed flames [7] and turbulent flow reactor oxidation [4], as well as ignition delay times [11, 12, 15] and laminar flame speeds [13, 14]. Table 2 summarizes the experimental data used to validate the present model. Comparisons of simulated results with previous experimental data are shown in Figs. S1-S10 in SMM \#1. The simulations of flow reactor pyrolysis, JSR oxidation, laminar premixed flames and laminar flame speeds were performed with the Plug Flow Reactor, Perfectly Stirred Reactor, Premixed Laminar Burner-Stabilized Flame and Premixed Laminar Flame-Speed Calculation modules in the ChemkinPro software [41], respectively. The simulations of turbulent flow reactor oxidation, RCM ignition delay times, shock tube oxidation and ignition delay times were carried out with the Closed Homogenous Batch Reactor module in the Chemkin-Pro software [41]. The reaction mechanism, thermodynamic data and transport data are provided in SMMs \#3, \#4 and \#5, respectively.

Table 2 Summary of the validation data of the present model.

\begin{tabular}{llllll} 
Experimental type & Reactor & $T / \mathrm{K}$ & $P / \mathrm{atm}$ & $\phi$ & References \\
\hline
\end{tabular}




\begin{tabular}{cccccc}
\hline Pyrolysis & Flow reactor & $1050-1625$ & $0.04,1$ & $\infty$ & This work \\
\hline \multirow{4}{*}{ Oxidation } & Flow reactor & 1150 & 1 & 1.1 & {$[4]$} \\
& JSR & $800-1200$ & 10 & $0.5,1.0,2.0$ & This work \\
& JSR & $900-1400$ & 1 & $0.5,1.0,1.5$ & {$[5]$} \\
& Shock tube & $1513-1877$ & 1.2 & 1.0 & {$[8]$} \\
& Laminar premixed flame & $500-2100$ & 0.04 & $0.75,1.0,1.79$ & {$[7]$} \\
\hline \multirow{3}{*}{ Ignition delay times } & Shock tube & $1400-1830$ & 1 & $0.5,1.0,2.0$ & {$[5]$} \\
& Shock tube & $1330-1800$ & $6.7-9$ & $0.5,1.0,2.0$ & {$[11]$} \\
& Shock tube & $941-1408$ & 10,40 & $0.5,1.0$ & {$[12]$} \\
\hline Laminar flame speeds & Counterflow twin flames & 353 & 1,2 & $0.7-1.5$ & {$[13,14]$} \\
\hline
\end{tabular}

\section{Results and discussion}

\subsection{Flow reactor pyrolysis}

Dozens of species were detected in the pyrolysis of $o$-xylene $\left(o-\mathrm{C}_{8} \mathrm{H}_{10}\right.$, the nomenclature in this model, see Table S4 in SMM \#1), including the critical resonantly stabilized radicals, e.g. $o$-xylyl ( $o$ $\left.\mathrm{C}_{8} \mathrm{H}_{9}\right)$, benzyl $\left(\mathrm{A}_{1} \mathrm{CH}_{2}\right)$, fulvenallenyl $\left(\mathrm{C}_{7} \mathrm{H}_{5}\right)$, cyclopentadienyl $\left(\mathrm{C}_{5} \mathrm{H}_{5}\right)$ and indenyl $\left(\mathrm{C}_{9} \mathrm{H}_{7}\right)$ radicals. Isomers were also identified, especially the three primary $\mathrm{C}_{8} \mathrm{H}_{8}$ isomers produced from the decomposition of $o$-xylyl, i.e. $o$-xylylene $\left(o-\mathrm{C}_{8} \mathrm{H}_{8}\right)$, styrene $\left(\mathrm{A}_{1} \mathrm{C}_{2} \mathrm{H}_{3}\right)$ and benzocyclobutene $\left(\mathrm{A} 1 \mathrm{cC}_{2} \mathrm{H}_{4}\right)$. Figure 1 illustrates the measured photoionization efficiency (PIE) spectra of $o$-xylyl and the three $\mathrm{C}_{8} \mathrm{H}_{8}$ isomers. In this section the primary decomposition process of $o$-xylene and PAH formation process are discussed, which involves some critical intermediates and abundantly produced products.

\subsubsection{Decomposition of o-xylene}

Figure 2 displays the experimental and simulated mole fraction profiles of $o$-xylene and $\mathrm{C}_{8}-\mathrm{C}_{7}$ products detected in the pyrolysis of $o$-xylene at 0.04 and $1 \mathrm{~atm}$. In general, the model can reasonably reproduce the experimental results. Styrene is observed as the most abundant $\mathrm{C}_{8}$ product in the pyrolysis of $o$-xylene with peak mole fractions of $2.3 \times 10^{-3}$ and $1.3 \times 10^{-3}$ at 0.04 and $1 \mathrm{~atm}$, as shown in Fig. 1(d). Compared with styrene, $o$-xylyl radical and toluene $\left(\mathrm{A}_{1} \mathrm{CH}_{3}\right)$ are formed at lower temperatures. In fact, the initial formation temperatures of the two products are close to the initial decomposition temperature of $o$-xylene, indicating that they are the primary decomposition products of $o$-xylene. In contrast, the initial formation temperatures of $o$-xylylene, benzyl and fulvenallene $\left(\mathrm{C}_{7} \mathrm{H}_{6}\right)$ are close to that of styrene. Therefore based on above observations, $o$-xylyl radical and toluene should be produced earlier than styrene, $o$-xylylene, benzyl and fulvenallene in the decomposition process of $o$-xylene.

\section{(1) Consumption of o-xylene}

To reveal key pathways in the decomposition of $o$-xylene, rate of production (ROP) and sensitivity analyses were performed at $1522 \mathrm{~K}, 0.04 \mathrm{~atm}$ and $1362 \mathrm{~K}, 1 \mathrm{~atm}$, corresponding to $70 \%$ conversion of $o$-xylene where most of products reach or are close to their peak mole fractions. The sensitivity analysis here is the relative response of mole fraction of the target species by changing the pre-exponential A-factor of the target reaction infinitesimally. The main reaction network of the fuel decomposition in the pyrolysis of $o$-xylene is shown in Fig. 3 according to the ROP analysis results. The ROP analysis shows that the pyrolysis of $o$-xylene is initiated by the $\mathrm{C}-\mathrm{H}$ bond dissociation reaction of the $\mathrm{CH}_{3}$ groups, which is similar to the pyrolysis of toluene [30]. The $\mathrm{C}-\mathrm{H}$ bond dissociation 
reaction is also a major consumption reaction of $o$-xylene, contributing around $20 \%$ and $10 \%$ to the consumption of $o$-xylene at 0.04 and $1 \mathrm{~atm}$, respectively. The $\mathrm{H}$-abstraction reaction by $\mathrm{H}$ is another major reaction and consumes over $50 \%$ of $o$-xylene at all pressures. Other consumption pathways of $o$-xylene include the ipso-substitution reaction by $\mathrm{H}$ and $\mathrm{H}$-abstraction reactions by other radicals. The sensitivity analysis results shown in Fig. 4 also reveal the key roles of these reactions in the consumption of $o$-xylene, while their roles vary with pressure. For example, $\mathrm{C}-\mathrm{H}$ bond dissociation reaction is the most sensitive reaction for the consumption of $o$-xylene at $0.04 \mathrm{~atm}$, while at $1 \mathrm{~atm}, \mathrm{H}-$ atom abstraction reactions have the largest sensitivity coefficients for the consumption of $o$-xylene.

\section{(2) Consumption of o-xylyl radical}

Due to the existence of ortho- $\mathrm{CH}_{3}$ group, the main decomposition pathways of $o$-xylyl radical are quite different from those of benzyl radical. The ROP analysis shows that $o$-xylyl radical tends to loss an $\mathrm{H}$ atom on the other $\mathrm{CH}_{3}$ group producing $o$-xylylene, while the decomposition of benzyl radical has to undergo ring-rearrangement processes with high energy barriers [43]. At all pressures this reaction contributes over $50 \%$ to the consumption of $o$-xylyl radical. Figure 4 shows that this reaction is a sensitive reactions for the consumption of $o$-xylene. $o$-Xylylene is mainly converted to styrene through direct isomerization or a reaction sequence via benzocyclobutene, which explains the abundant production of styrene at all pressures.

$o$-Xylyl radical can also isomerize to $m$-xylyl $\left(m-\mathrm{C}_{8} \mathrm{H}_{9}\right)$ radical. As shown in Fig. 4 , this reaction can inhibit the consumption of $o$-xylene, especially at $0.04 \mathrm{~atm}$, since $m$-xylyl radical is quite stable and cannot decompose by losing an $\mathrm{H}$ atom like $o$-xylyl does. Under the investigated conditions, $m$ xylyl radical tends to undergo $\mathrm{H}$-addition reaction to form $m$-xylene, which is a typical chaintermination reaction and can also suppress the pyrolysis reactivity of $o$-xylene, as shown in Fig. 4. Other consumption pathways of $o$-xylyl radical include the unimolecular decomposition reactions to produce 2-methylfulvenallene $\left(\mathrm{C}_{7} \mathrm{H}_{5} \mathrm{CH}_{3}\right)+\mathrm{H}$, fulvenallene $+\mathrm{CH}_{3}$ and benzocyclobutene $+\mathrm{H}$, the reaction with $\mathrm{H}$ to produce benzyl $+\mathrm{CH}_{3}$ and the decomposition reaction to produce methylcyclopentadienyl $\left(\mathrm{C}_{5} \mathrm{H}_{4} \mathrm{CH}_{3}\right)+$ acetylene and cyclopentadiene $\left(\mathrm{C}_{5} \mathrm{H}_{6}\right)+$ propargyl $\left(\mathrm{C}_{3} \mathrm{H}_{3}\right)$. As shown in Fig. 3, these reaction pathways have very similar contributions to the consumption of $o$-xylyl radical and are the major formation pathways of benzyl, fulvenallene and cyclopentadiene. It should be noted that the self-combination reaction only have minor contribution to the consumption of $o$-xylyl radical, even at $1 \mathrm{~atm}$, which is different from the situation of benzyl radical in the pyrolysis of toluene [30].

\section{(3) Formation of pyrolysis intermediates}

Figure 5 shows the results of $\mathrm{C}_{9}-\mathrm{C}_{4}$ products in the pyrolysis of $o$-xylene. These species are mainly produced through the further decomposition/recombination reactions of the primary decomposition products, e.g. styrene, $o$-xylyl and fulvenallene. For example, $o$-methylethylbenzene $\left(o-\mathrm{CH}_{3} \mathrm{C}_{6} \mathrm{H}_{4} \mathrm{C}_{2} \mathrm{H}_{5}\right)$ is dominantly produced from the addition reaction of $o$-xylyl with $\mathrm{CH}_{3}$, while phenylacetylene $\left(\mathrm{A}_{1} \mathrm{C}_{2} \mathrm{H}\right)$ is produced via the stepwise H-loss reactions of styrene. It is interesting to observe that the peak mole fraction of $o$-methylethylbenzene decreases dramatically with the increasing pressure. This is different from the trend of ethylbenzene $\left(\mathrm{A}_{1} \mathrm{C}_{2} \mathrm{H}_{5}\right)$, i.e. the product of the addition reaction of benzyl with $\mathrm{CH}_{3}$, in the pyrolysis of toluene [30]. The ROP analysis reveals that in the pyrolysis of $o$-xylene, the reduced formation of $o$-methylethylbenzene at $1 \mathrm{~atm}$ is caused by the enhanced competing pathways like selfcombination and isomerization reactions in the consumption of $o$-xylyl as pressure increases. As shown in Fig. 5(d), the peak mole fractions of benzene (A1) reach $1 \times 10^{-3}$ at both pressures, making it one of the most abundant products in the pyrolysis of $o$-xylene. The ROP analysis shows that benzene is mainly produced from the unimolecular decomposition reaction of styrene $\left(\mathrm{A}_{1} \mathrm{C}_{2} \mathrm{H}_{3}=\mathrm{A} 1+\mathrm{H}_{2} \mathrm{CC}\right)$ [44] and the ipso-substitution reaction of styrene by $\mathrm{H}\left(\mathrm{A}_{1} \mathrm{C}_{2} \mathrm{H}_{3}+\mathrm{H}=\mathrm{A} 1+\mathrm{C}_{2} \mathrm{H}_{3}\right)$ [45]. 
Figure 6 displays the experimental and simulated mole fraction profiles of $\mathrm{C}_{4}-\mathrm{C}_{0}$ products in the pyrolysis of $o$-xylene. Among these small products, the peak mole fractions of $\mathrm{C}_{2}-\mathrm{C}_{4}$ products decrease as pressure increases. According to the ROP analysis results, the main formation pathways of $\mathrm{C}_{2}-\mathrm{C}_{3}$ products are closely related to the decomposition reactions of aforementioned important pyrolysis products of $o$-xylene. For example, acetylene $\left(\mathrm{C}_{2} \mathrm{H}_{2}\right)$ is mainly produced from the isomerization of vinylidene $\left(\mathrm{H}_{2} \mathrm{CC}\right)$, which is the other product besides benzene in the unimolecular decomposition reaction of styrene. At both pressures, around $50 \%$ of acetylene is produced via the isomerization of vinylidene, while another $15 \%$ is produced from the decomposition of vinyl $\left(\mathrm{C}_{2} \mathrm{H}_{3}\right)$, which is also dominantly produced from the ipso-substitution reaction of styrene by $\mathrm{H}$. Other formation pathways of acetylene include the decomposition reactions of $o$-xylyl, fulvenallene and phenylacetylene. Besides acetylene, the decomposition reaction of styrene $\left(\mathrm{A} 1-+\mathrm{C}_{2} \mathrm{H}_{4}=\mathrm{A}_{1} \mathrm{C}_{2} \mathrm{H}_{3}+\mathrm{H}\right)$ [46] is a major formation pathway of ethylene $\left(\mathrm{C}_{2} \mathrm{H}_{4}\right)$. Furthermore, diacetylene is also observed as a major pyrolysis product of $o$-xylene at $0.04 \mathrm{~atm}$, as shown in Fig. 6(a). According to the ROP analysis, over $95 \%$ of diacetylene is formed from the unimolecular decomposition reaction of fulvenallenyl which is mainly produced from the decomposition of fulvenallene.

\subsubsection{Formation and growth of PAHs}

Figure 7 displays the experimental and simulated mole fraction profiles of typical PAH species detected in this work. It can be observed from Fig. 7 that the production of PAHs is generally enhanced as pressure increases. The ROP analysis was also performed to reveal the main PAH formation pathways at $1522 \mathrm{~K}, 0.04 \mathrm{~atm}$ and $1362 \mathrm{~K}, 1 \mathrm{~atm}$, as shown in Fig. 8. Furthermore, three groups of major PAH products are observed, i.e. $\mathrm{C}_{9}$ PAHs, naphthalene (A2) and its methyl derivatives, phenanthrene (A3) and its methyl derivatives. For each group, Fig. 9 compares their summed mole fraction with that in the pyrolysis of toluene [30].

Indene $\left(\mathrm{C}_{9} \mathrm{H}_{8}\right)$, indenyl $\left(\mathrm{C}_{9} \mathrm{H}_{7}\right)$ and indane $\left(\mathrm{C}_{9} \mathrm{H}_{10}\right)$ are observed as the major $\mathrm{C}_{9}$ PAHs in the pyrolysis of $o$-xylene, which is one group of major PAH products in the pyrolysis of $o$-xylene. According to the ROP analysis, indene is mainly produced from the reaction between fulvenallene and acetylene [47], $\mathrm{CH}_{3}$ addition/cyclization reaction sequence of $o$-vinylphenyl $\left(\mathrm{C}_{6} \mathrm{H}_{4} \mathrm{C}_{2} \mathrm{H}_{3}\right)$ radical [48] and addition reaction of benzyl radical with acetylene. As discussed above, all of these precursors can be significantly produced in the pyrolysis of $o$-xylene. Besides, the dominant formation pathways of indene are found to vary with pressure. At $0.04 \mathrm{~atm}$ when the concentration of $\mathrm{CH}_{3}$ is higher, indene is dominantly produced through the $\mathrm{CH}_{3}$ addition/cyclization reaction sequence of $o$-vinylphenyl radical. At $1 \mathrm{~atm}$, the reaction between fulvenallene and acetylene has a greater contribution to indene formation. Indane is another important $\mathrm{C}_{9} \mathrm{PAH}$ observed in the pyrolysis of $o$-xylene. At $1 \mathrm{~atm}$, the peak mole fraction of indane reaches around $2.5 \times 10^{-4}$, which is at the same level as that of indene. The abundant production of indane implies that some fuel-specific pathways may contribute to its formation, because it is hard to form this kind of hydrogenated PAH via recombination reactions. According to the ROP analysis, indane is mainly generated via the dehydrogenation/cyclization reactions of $o$-ethylbenzyl radical, which is the recombination product of $o$-xylyl and methyl.

Naphthalene is the most important $\mathrm{C}_{10} \mathrm{PAH}$ observed in the pyrolysis of $o$-xylene. The reaction between 1-phenylvinyl $\left(\mathrm{A}_{1} \mathrm{CCH}_{2}\right)$ and acetylene [49] and the recombination between fulvenallenyl and propargyl are two major formation pathways of naphthalene. The dominant formation pathway of naphthalene also varies with pressure. At $0.04 \mathrm{~atm}$ when fulvenallenyl and propargyl have high concentration levels, the later pathway dominates the production of naphthalene with a contribution of over 50\%. At $1 \mathrm{~atm}$, the reaction between 1-phenylvinyl and acetylene becomes the dominant pathway. Naphthalene can also formed through the ring-rearrangement reaction of 1-methyleneindan-2-yl $\left(\mathrm{C}_{9} \mathrm{H}_{7} \mathrm{CH}_{2}\right)$ radical, which is mainly produced from the recombination reaction between benzyl and 
propargyl. In the pyrolysis of toluene [30], this pathway has dominant contributions to naphthalene formation. However in the pyrolysis of $o$-xylene, this pathway has only minor contributions to naphthalene formation due to the limited production of benzyl.

Phenanthrene and its methyl derivatives are the other major group of PAHs observed in the pyrolysis of $o$-xylene, as can be seen from Figs. 7 and 9. Their peak mole fractions follow the order of phenanthrene $>$ methylphenanthrene $\left(\mathrm{A}_{3} \mathrm{CH}_{3}\right)>$ dimethylphenanthrene $\left(\mathrm{A} 3\left(\mathrm{CH}_{3}\right)_{2}\right)$. For phenanthrene, the self-combination reaction of fulvenallenyl contributes over $40 \%$ of its formation at $0.04 \mathrm{~atm}$. At 1 atm, phenanthrene is mainly produced from the stepwise $\mathrm{H}$-loss/cyclization reaction sequence of bibenzyl $\left(\mathrm{C}_{14} \mathrm{H}_{14}\right)$ which is the self-combination product of benzyl radical. Apart from phenanthrene, methylphenanthrene and dimethylphenanthrene are also observed as abundantly-produced tricyclic PAHs. It should be noted that phenanthrene and its methyl derivatives are also a major group of PAHs produced in the pyrolysis of toluene [30], as shown in Fig. 9. By analogy to the formation pathways of phenanthrene, the fuel-specific formation pathways of methylphenanthrene and dimethylphenanthrene were proposed in this work, as illustrated in Fig. 8. The ROP analysis results show that the formations of methylphenanthrene and dimethylphenanthrene at 1 atm are mainly controlled by the stepwise H-loss/cyclization reaction sequences of 2-methylbibenzyl and 2,2'dimethylbibenzyl, which are produced from the addition reaction of $o$-xylyl with benzyl and selfcombination reaction of $o$-xylyl, respectively. At low pressure, the addition reaction of 2methylfulvenallenyl with fulvenallenyl and the self-combination reaction of 2-methylfulvenallenyl contribute to the formation of most of dimethylphenanthrene and methylphenanthrene, respectively.

\subsection{JSR oxidation}

Dozens of oxidation species were also detected in the JSR oxidation of $o$-xylene at $10 \mathrm{~atm}$ and $\phi$ $=0.5,1.0$ and 2.0. The oxidation products are classified as aromatic products, oxygenated aromatic products, PAHs and $\mathrm{C}_{5}-\mathrm{C}_{0}$ products. This section focuses on the decomposition process of $o$-xylene, oxygenated aromatics formation chemistry and PAH formation chemistry under high pressure oxidation conditions.

\subsubsection{Decomposition of o-xylene}

Experimental and simulated mole fraction profiles of $o$-xylene and major aromatic products are displayed in Fig. 10. The present model can well capture the oxidation reactivity of $o$-xylene at different equivalence ratios. Toluene and benzene belong to the abundantly produced aromatic products while the production of styrene is not as favoured as the situation under pyrolysis conditions. The ROP analysis was performed at $975 \mathrm{~K}$ and $\phi=1.0$ to provide insights into the oxidation chemistry of $o$-xylene. Under lean and rich conditions, the major decomposition and oxidation pathways of $o$ xylene are similar to those under the stoichiometric condition. According to the ROP analysis results, main reaction network in the oxidation of $o$-xylene is summarized in Fig. 11. It should be noted that the main consumption pathways of $o$-xylene and the main formation/consumption pathways of major products have little differences at different equivalence ratios. The fuel is mainly consumed through the $\mathrm{H}$-abstraction reaction by $\mathrm{OH}, \mathrm{O}, \mathrm{H}$ and $\mathrm{HO}_{2}$, producing $o$-xylyl radical. Other consumption reactions include the $\mathrm{H}$-abstraction reaction producing dimethylphenyl radical and the ipsosubstitution reaction by $\mathrm{H}$ producing toluene and $\mathrm{CH}_{3}$.

\subsubsection{Oxidation of o-xylyl and formation of oxygenated aromatics}

The $o$-xylyl radical mainly undergoes the oxidation reaction with $\mathrm{HO}_{2}$, producing $o$ methylbenzoxyl $\left(o-\mathrm{CH}_{3} \mathrm{C}_{6} \mathrm{H}_{4} \mathrm{CH}_{2} \mathrm{O}\right)+\mathrm{OH}$ directly or through $o$-methylbenzyl hydroperoxide $(o-$ $\left.\mathrm{CH}_{3} \mathrm{C}_{6} \mathrm{H}_{4} \mathrm{CH}_{2} \mathrm{OOH}\right)$. Further decomposition of $o$-methylbenzoxyl radical mainly produces $o$ methylbenzaldehyde $\left(o-\mathrm{CH}_{3} \mathrm{C}_{6} \mathrm{H}_{4} \mathrm{CHO}\right)$ by losing an $\mathrm{H}$ atom and partly produces toluene + formyl 
( $\mathrm{HCO})$ and methylphenyl $\left(\mathrm{C}_{6} \mathrm{H}_{4} \mathrm{CH}_{3}\right)+$ formaldehyde $\left(\mathrm{CH}_{2} \mathrm{O}\right)$. As a result, $o$-methylbenzaldehyde is the most abundantly produced oxygenated aromatics in the oxidation of $o$-xylene. $o$ Methylbenzaldehyde mainly decays through the H-loss reaction producing $o$-methylbenzoyl radical, followed by decarbonylation reaction producing methylphenyl radical. Further oxidation of methylphenyl radical by $\mathrm{O}_{2}$ produces $o$-methylphenoxy $\left(\mathrm{OC}_{6} \mathrm{H}_{4} \mathrm{CH}_{3}\right)$ radical and $o$-benzoquinone $(o$ $\mathrm{C}_{6} \mathrm{H}_{4} \mathrm{O}_{2}$ ) as major products. The former product prefers to add an $\mathrm{H}$ atom to form cresol (Fig. 14(b)), which is also an important oxygenated aromatic product in the oxidation of $o$-xylene. Part of $o$ methylphenoxy radical may also isomerize to $o$-hydroxybenzyl $\left(o-\mathrm{CH}_{2} \mathrm{C}_{6} \mathrm{H}_{4} \mathrm{OH}\right)$ radical, while further oxidation reactions of $o$-hydroxybenzyl radical are the main source of phenoxy (A1O) radical in the oxidation of $o$-xylene. Benzofuran $\left(\mathrm{C}_{8} \mathrm{H}_{6} \mathrm{O}\right)$ is an important oxygenated aromatic product in the oxidation of $o$-xylene, as well as the oxidation of styrene [29] and ethylbenzene [32]. As illustrated in Fig. 12(d), the peak mole fraction of benzofuran increases from lean to rich conditions. The ROP analysis indicates that two main pathways contribute to the formation of benzofuran, i.e. the reaction of phenoxy radical and acetylene and the ring-closure reaction of $o$-vinylphenoxy $\left(\mathrm{OC}_{6} \mathrm{H}_{4} \mathrm{C}_{2} \mathrm{H}_{3}\right)$ radical, as shown in Fig. 11. However the model under-predicts the formation of benzofuran, especially the observed increasing trend with the increasing equivalence ratio, which reveals the need of further investigation on the formation and consumption pathways of benzofuran.

\subsubsection{Formation of PAHs}

Indene and naphthalene are two major PAHs detected in the present oxidation experiments. It can be observed from Fig. 13(b) that the measured peak mole fraction of indene decreases with the increasing equivalence ratio. The model is able to predict the formation of indene under the rich condition while under-predicts its formation under lean and stoichiometric conditions. The main formation pathways of indene is contributed by the stepwise $\mathrm{H}$-loss/cyclization reaction sequence of $o$-methylethylbenzene, which is mainly produced from the addition reaction of $o$-xylyl with methyl. Additional pathways may contribute to the formation of indene under lean and stoichiometric conditions, which deserves further studies in the future. In contrast to indene, the measured peak mole fraction of naphthalene increases with the increasing equivalence ratio. The dominant formation pathway of naphthalene is totally different from that under pyrolysis conditions. At all equivalence ratios, naphthalene is dominantly produced form the decomposition of dibenzofuran, while the latter species is produced from the self-combination of phenoxy.

\subsubsection{Formation of $C_{5}$ and smaller products}

Figure 13(d-i) shows the experimental and simulated mole fraction profiles of $\mathrm{C}_{5}-\mathrm{C}_{3}$ hydrocarbon products. As equivalence ratio increases, the peak mole fractions of cyclopentadiene, 1,3-butadiene $\left(\mathrm{C}_{4} \mathrm{H}_{6}\right)$, propyne $\left(\mathrm{p}-\mathrm{C}_{3} \mathrm{H}_{4}\right)$ and allene $\left(\mathrm{a}-\mathrm{C}_{3} \mathrm{H}_{4}\right)$ only slightly increase, while the peak mole fraction of vinylacetylene $\left(\mathrm{C}_{4} \mathrm{H}_{4}\right)$ has a remarkable increase. The ROP analysis shows that the major formation pathways of former species do not vary with equivalence ratios, except for the slight changes in reaction fluxes. For vinylacetylene, it can be abundantly formed from the decomposition of cyclopentadienone under the rich condition, while under the lean condition, its formation is inhibited due to the strong competition from the oxidation reaction of cyclopentadienone by $\mathrm{O}$ and $\mathrm{OH}$.

Figure 14 presents the experimental and simulated mole fraction profiles of $\mathrm{C}_{2}-\mathrm{C}_{0}$ species and $\mathrm{O}_{2}$. In comparison with the $o$-xylene oxidation experiments at $1 \mathrm{~atm}$ [5], the peak mole fractions of ethane, ethylene, acetylene and methane at 10 atm have only slight changes, while the peak mole fractions of formaldehyde are almost doubled. The ROP analysis at the two pressures show that the decomposition reaction of $o$-methylbenzoxyl becomes an additional main formation pathway of formaldehyde at 10 atm, leading to the enhanced formation of formaldehyde at $10 \mathrm{~atm}$. 


\section{Conclusions}

The flow reactor pyrolysis and JSR oxidation of $o$-xylene were investigated in this work at various pressures, focusing on the decomposition and oxidation chemistry of $o$-xylene and the PAH formation mechanism. A kinetic model was developed based on our previous models of aromatic fuels and recent theoretical progress on $o$-xylyl reactions. The model was also validated against available experimental data of $o$-xylene combustion. Key decomposition products of $o$-xylene, such as $o$-xylyl radical, $o$ xylylene/benzocyclobutene/styrene isomers and fulvenallene were detected. The pyrolysis of $o$-xylene mainly produces $o$-xylyl radical. $o$-Xylyl radical mainly decomposes to $o$-xylylene which further converts to styrene directly or through benzocyclobutene. In the pyrolysis of $o$-xylene, $\mathrm{C}_{9} \mathrm{PAHs}$ (indenyl, indene and indane), phenanthrene and methylphenanthrenes belong to the abundantly produced bicyclic and tricyclic PAHs, respectively. The PAH formation pathways initiated from $o$ xylyl radical were also investigated. The dominant formation pathways of major bicyclic and tricyclic PAHs differ at low and atmospheric pressures. Fuel-specific pathways contribute to the formation of some PAHs, such as methylphenanthrene and dimethylphenanthrene produced by reaction sequences initiated from the self-combination of $o$-xylyl and addition of $o$-xylyl with benzyl, respectively. $O$ Xylyl radical is also the dominant fuel consumption product in the JSR oxidation of $o$-xylene. The consumption of $o$-xylyl radical mainly proceeds through the oxidation by $\mathrm{HO}_{2}$ and finally produces $o$ methylbenzaldehyde. The further decomposition reactions of $o$-methylbenzaldehyde contribute to the formation of other major oxygenated aromatics like cresol and benzofuran. PAHs like indene and naphthalene were also observed in the oxidation of $o$-xylene. Indene is mainly produced from the stepwise H-loss/cyclization reaction sequence of $o$-methylethylbenzene, while naphthalene is mainly produced via the decomposition reaction of dibenzofuran, which is generated from the selfcombination of phenoxyl.

\section{Acknowledgements}

The authors are grateful to the funding support from the National Natural Science Foundation of China (51706137, 91641205, U1832171, 91841301) and National Key R\&D Program of China (2019YFA0405602).

\section{References}

[1] S. M. Sarathy, A. Farooq, G. T. Kalghatgi, Recent progress in gasoline surrogate fuels, Prog. Energy Combust. Sci. 65 (2018) 67-108.

[2] C. S. McEnally, L. D. Pfefferle, Improved sooting tendency measurements for aromatic hydrocarbons and their implications for naphthalene formation pathways, Combust. Flame 148 (2007) 210-222.

[3] G. Da Silva, J. W. Bozzelli, On the reactivity of methylbenzenes, Combust. Flame 157 (2010) $2175-2183$.

[4] J. Emdee, K. Brezinsky, I. Glassman, Oxidation of $o$-xylene, Proc. Combust. Inst. 23 (1991) 77-84.

[5] S. Gaïl, P. Dagaut, G. Black, J. M. Simmie, Kinetics of 1, 2-dimethylbenzene oxidation and ignition: experimental and detailed chemical kinetic modeling, Combust. Sci. Technol. 180 (2008) 1748-1771.

[6] Y. Y. Li, L. D. Zhang, T. Yuan, K. W. Zhang, J. Z. Yang, B. Yang, F. Qi, C. K. Law, Investigation on fuel-rich premixed flames of monocyclic aromatic hydrocarbons: Part I. Intermediate identification and mass spectrometric analysis, Combust. Flame 157 (2010) 143-154.

[7] L. Zhao, Z. J. Cheng, L. L. Ye, F. Zhang, L. D. Zhang, F. Qi, Y. Y. Li, Experimental and kinetic modeling study of premixed $o$-xylene flames, Proc. Combust. Inst. 35 (2015) 1745-1752.

[8] S. K. Wang, D. F. Davidson, R. K. Hanson, Shock tube measurements of OH concentration time-histories in benzene, toluene, ethylbenzene and xylene oxidation, Proc. Combust. Inst. 37 (2019) 163-170. 
A. Roubaud, O. Lemaire, R. Minetti, L. Sochet, High pressure auto-ignition and oxidation mechanisms of $o$ xylene, $o$-ethyltoluene, and $n$-butylbenzene between 600 and $900 \mathrm{~K}$, Combust. Flame 123 (2000) 561-571.

[10] A. Roubaud, R. Minetti, L. Sochet, Oxidation and combustion of low alkylbenzenes at high pressure: comparative reactivity and auto-ignition, Combust. Flame 121 (2000) 535-541.

[11] F. Battin-Leclerc, R. Bounaceur, N. Belmekki, P. Glaude, Experimental and modeling study of the oxidation of xylenes, Int. J. Chem. Kinet. 38 (2006) 284-302.

[12] H.-P. S. Shen, M. A. Oehlschlaeger, The autoignition of $\mathrm{C}_{8} \mathrm{H}_{10}$ aromatics at moderate temperatures and elevated pressures, Combust. Flame 156 (2009) 1053-1062.

[13] C. S. Ji, E. Dames, H. Wang, F. N. Egolfopoulos, Propagation and extinction of benzene and alkylated benzene flames, Combust. Flame 159 (2012) 1070-1081.

[14] D. Han, S. L. Deng, W. K. Liang, P. Zhao, F. J. Wu, Z. Huang, C. K. Law, Laminar flame propagation and nonpremixed stagnation ignition of toluene and xylenes, Proc. Combust. Inst. 36 (2017) 479-489.

[15] G. Kukkadapu, D. Kang, S. W. Wagnon, K. W. Zhang, M. Mehl, M. Monge-Palacios, H. Wang, S. S. Goldsborough, C. K. Westbrook, W. J. Pitz, Kinetic modeling study of surrogate components for gasoline, jet and diesel fuels: $\mathrm{C}_{7}-\mathrm{C}_{11}$ methylated aromatics, Proc. Combust. Inst. 37 (2019) 521-529.

[16] J. H. Cai, L. D. Zhang, F. Zhang, Z. D. Wang, Z. J. Cheng, W. H. Yuan, F. Qi, Experimental and kinetic modeling study of $n$-butanol pyrolysis and combustion, Energy Fuels 26 (2012) 5550-5568.

[17] F. Qi, Combustion chemistry probed by synchrotron VUV photoionization mass spectrometry, Proc. Combust. Inst. 34 (2013) 33-63.

[18] Y. Zhang, C. C. Cao, Y. Y. Li, W. H. Yuan, X. Y. Yang, J. Z. Yang, F. Qi, T.-P. Huang, Y.-Y. Lee, Pyrolysis of $n-$ butylbenzene at various pressures: influence of long side-chain structure on alkylbenzene pyrolysis, Energy Fuels 31 (2017) 14270-14279.

[19] Z. Y. Zhou, X. W. Du, J. Z. Yang, Y. Z. Wang, C. Y. Li, S. Wei, L. L. Du, Y. Y. Li, F. Qi, Q. P. Wang, The vacuum ultraviolet beamline/endstations at NSRL dedicated to combustion research, J. Synchrotron Radiat. 23 (2016) 1035-1045.

[20] C. Narayanan, S. Srinivasan, A. K. Datye, R. Gorte, A. Biaglow, The effect of alumina structure on surface sites for alcohol dehydration, J. Catal. 138 (1992) 659-674.

[21] Z. J. Cheng, L. L. Xing, M. R. Zeng, W. L. Dong, F. Zhang, F. Qi, Y. Y. Li, Experimental and kinetic modeling study of 2, 5-dimethylfuran pyrolysis at various pressures, Combust. Flame 161 (2014) 2496-2511.

[22] M. Cathonnet, J. C. Boettner, H. James, Experimental study and numerical modeling of high temperature oxidation of propane and n-butane, Proc. Combust. Inst. 18 (1981) 903-913.

[23] P. Glarborg, P. G. Kristensen, S. H. Jensen, K. Dam-Johansen, A flow reactor study of HNCO oxidation chemistry, Combust. Flame 98 (1994) 241-258.

[24] P. G. Kristensen, P. Glarborg, K. Dam-Johansen, Nitrogen chemistry during burnout in fuel-staged combustion, Combust. Flame 107 (1996) 211-222.

[25] Y. Y. Li, F. Qi, Recent applications of synchrotron VUV photoionization mass spectrometry: Insight into combustion chemistry, Acc. Chem. Res. 43 (2010) 68-78.

[26] Y. J. Zhang, J. H. Cai, L. Zhao, J. Z. Yang, H. F. Jin, Z. J. Cheng, Y. Y. Li, L. D. Zhang, F. Qi, An experimental and kinetic modeling study of three butene isomers pyrolysis at low pressure, Combust. Flame 159 (2012) 905917.

[27] P. Dagaut, M. Reuillon, M. Cathonnet, Experimental study of the oxidation of $n$-heptane in a jet stirred reactor from low to high temperature and pressures up to $40 \mathrm{~atm}$, Combust. Flame 101 (1995) 132-140.

[28] Z. Serinyel, C. Togbé, A. Zaras, G. Dayma, P. Dagaut, Kinetics of oxidation of cyclohexanone in a jet-stirred reactor: Experimental and modeling, Proc. Combust. Inst. 35 (2015) 507-514.

[29] W. H. Yuan, Y. Y. Li, P. Dagaut, J. Z. Yang, F. Qi, Experimental and kinetic modeling study of styrene combustion, Combust. Flame 162 (2015) 1868-1883.

[30] W. H. Yuan, Y. Y. Li, P. Dagaut, J. Z. Yang, F. Qi, Investigation on the pyrolysis and oxidation of toluene over a 
wide range conditions. I. Flow reactor pyrolysis and jet stirred reactor oxidation, Combust. Flame 162 (2015) 321.

[31] W. H. Yuan, Y. Y. Li, P. Dagaut, J. Z. Yang, F. Qi, Investigation on the pyrolysis and oxidation of toluene over a wide range conditions. II. A comprehensive kinetic modeling study, Combust. Flame 162 (2015) 22-40.

[32] W. H. Yuan, Y. Y. Li, G. Pengloan, C. Togbé, P. Dagaut, F. Qi, A comprehensive experimental and kinetic modeling study of ethylbenzene combustion, Combust. Flame 166 (2016) 255-265.

[33] K. Pachner, M. Steglich, P. Hemberger, I. Fischer, Photodissociation dynamics of the ortho-and para-xylyl radicals, J. Chem. Phys. 147 (2017) 084303.

[34] G. da Silva, E. E. Moore, J. W. Bozzelli, Decomposition of methylbenzyl radicals in the pyrolysis and oxidation of xylenes, J. Phys. Chem. A 113 (2009) 10264-10278.

[35] N. J. Reilly, G. da Silva, C. M. Wilcox, Z. J. Ge, D. L. Kokkin, T. P. Troy, K. Nauta, S. H. Kable, M. C. McCarthy, T. W. Schmidt, Interconversion of methyltropyl and xylyl radicals: a pathway unavailable to the benzyl-tropyl rearrangement, J. Phys. Chem. A 122 (2018) 1261-1269.

[36] P. Hemberger, A. J. Trevitt, E. Ross, G. da Silva, Direct observation of para-xylylene as the decomposition product of the meta-xylyl radical using vuv synchrotron radiation, J. Phys. Chem. Lett. 4 (2013) 2546-2550.

[37] P. Hemberger, A. J. Trevitt, T. Gerber, E. Ross, G. da Silva, Isomer-specific product detection of gas-phase xylyl radical rearrangement and decomposition using VUV synchrotron photoionization, J. Phys. Chem. A 118 (2014) 3593-3604.

[38] M. Braun-Unkhoff, P. Frank, T. Just, High-temperature reactions of benzyl radicals, Ber. Bunsen-Ges. Phys.Chem. 94 (1990) 1417-1425.

[39] Jeffrey, Jones, George, B., Bacskay, John, C., Mackie, Decomposition of the benzyl radical: Quantum chemical and experimental (Shock Tube) investigations of reaction pathways, J. Phys. Chem. A 101 (1997) 7105-7113.

[40] E. R. Ritter, J. W. Bozzelli, THERM: Thermodynamic property estimation for gas phase radicals and molecules, Int. J. Chem. Kinet. 23 (1991) 767-778.

[41] CHEMKIN-PRO 15092, Reaction Design: San Diego, 2009.

[42] Z. Y. Zhou, M. F. Xie, Z. D. Wang, F. Qi, Determination of absolute photoionization cross sections of aromatics and aromatic derivatives, Rapid Commun. Mass Spectrom. 23 (2009) 3994-4002.

[43] G. da Silva, J. A. Cole, J. W. Bozzelli, Thermal decomposition of the benzyl radical to fulvenallene $\left(\mathrm{C}_{7} \mathrm{H}_{6}\right)+\mathrm{H}_{\text {, J. }}$ Phys. Chem. A 113 (2009) 6111-6120.

[44] K. Narayanaswamy, G. Blanquart, H. Pitsch, A consistent chemical mechanism for oxidation of substituted aromatic species, Combust. Flame 157 (2010) 1879-1898.

[45] I. V. Tokmakov, M. C. Lin, Combined quantum chemical/RRKM-ME computational study of the phenyl + ethylene, vinyl + benzene, and H + styrene reactions, J. Phys. Chem. A 108 (2004) 9697-9714.

[46] A. Fahr, S. E. Stein, Reactions of vinyl and phenyl radicals with ethyne, ethene and benzene, Proc. Combust. Inst. 22 (1989) 1023-1029.

[47] G. d. Silva, J. W. Bozzelli, Indene formation from alkylated aromatics: kinetics and products of the fulvenallene+ acetylene reaction, J. Phys. Chem. A 113 (2009) 8971-8978.

[48] A. Laskin, A. Lifshitz, Thermal decomposition of indene. Experimental results and kinetic modeling, Proc. Combust. Inst. 27 (1998) 313-320.

[49] G. Blanquart, P. Pepiot-Desjardins, H. Pitsch, Chemical mechanism for high temperature combustion of engine relevant fuels with emphasis on soot precursors, Combust. Flame 156 (2009) 588-607. 


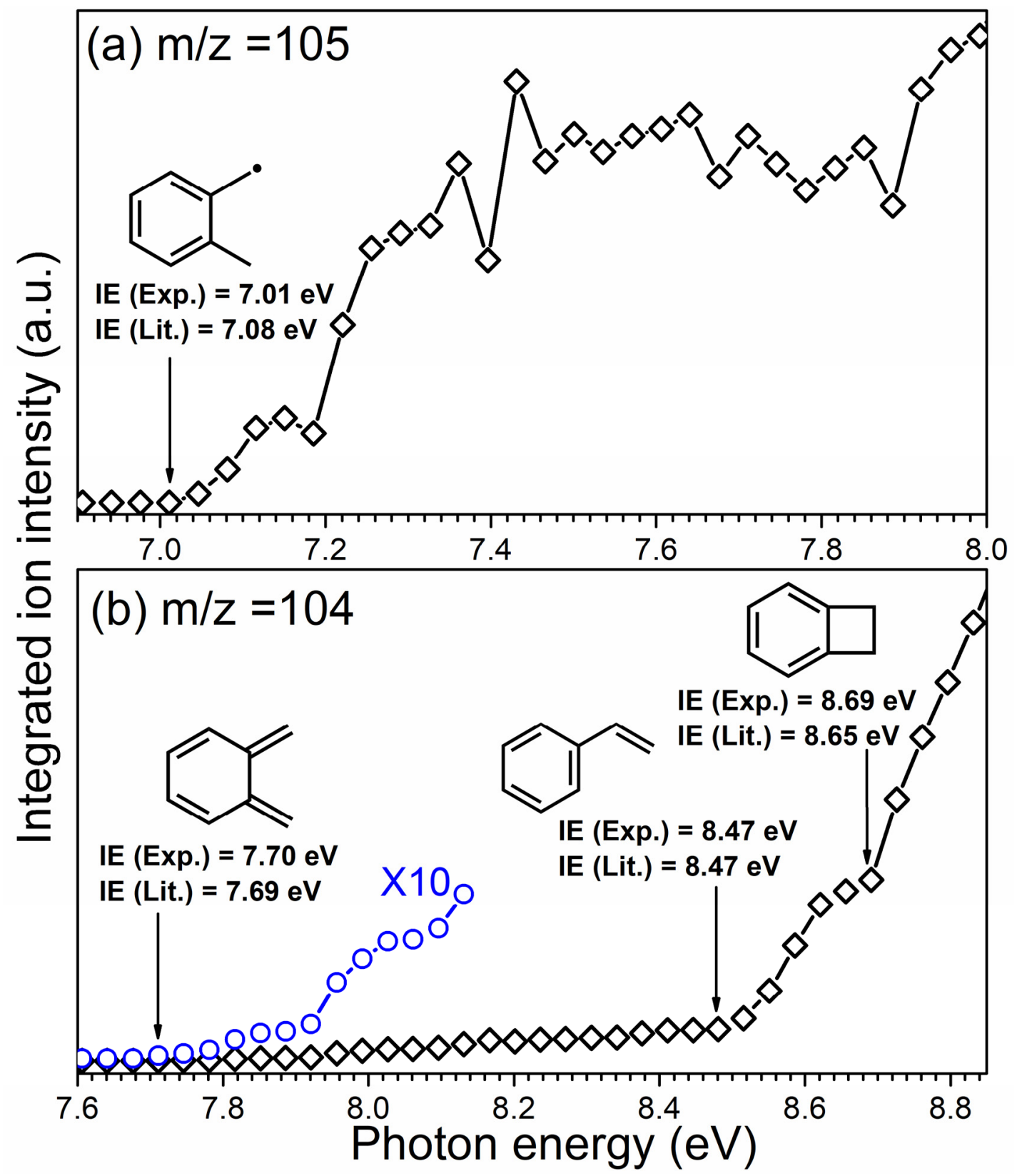

Fig. 1 Measured PIE spectra of (a) $\mathrm{C}_{8} \mathrm{H}_{9}(\mathrm{~m} / \mathrm{z}=105)$ and (b) $\mathrm{C}_{8} \mathrm{H}_{8}(\mathrm{~m} / \mathrm{z}=104)$ in the flow reactor pyrolysis of $o$-xylene at $0.04 \mathrm{~atm}$. IE (Exp.) and IE (Lit.) denote the measured and literature ionization energies (IEs) of $o$-xylyl radical [37], $o$-xylylene [37], styrene [42] and benzocyclobutene [37], respectively. 


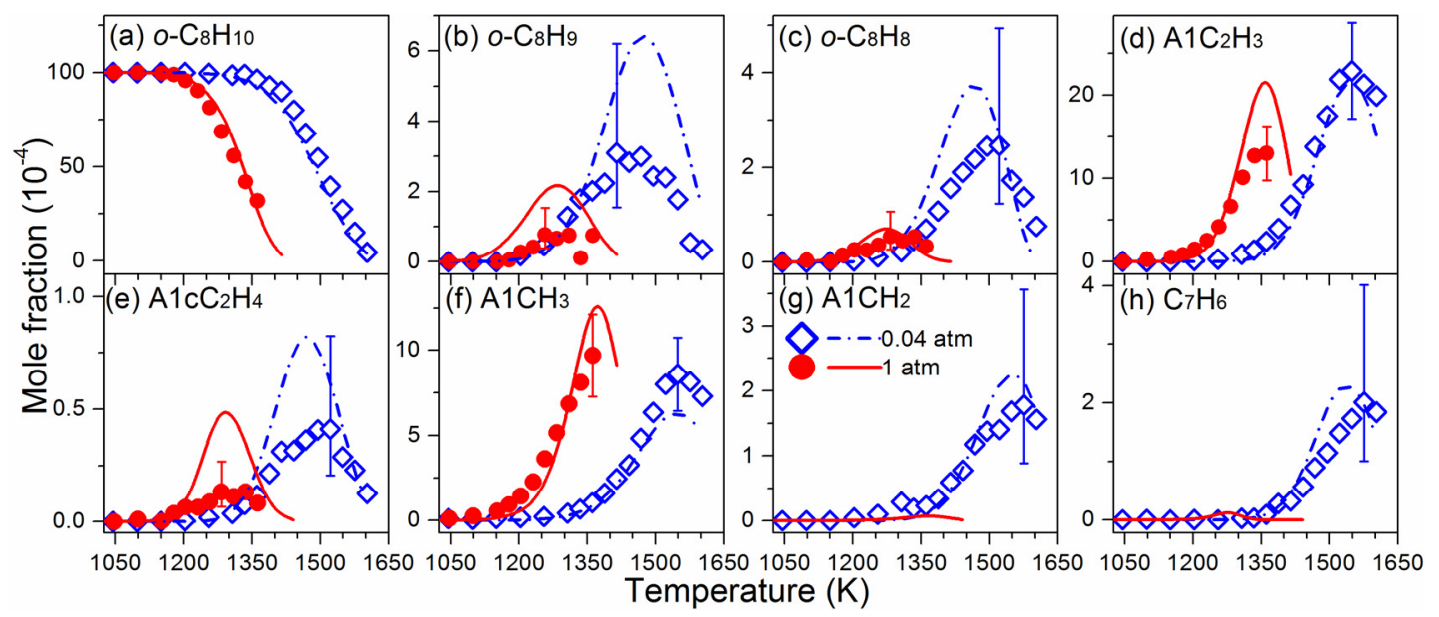

Fig. 2 Experimental (symbols) and simulated (lines) mole fraction profiles of fuel and several $\mathrm{C}_{8}-$ $\mathrm{C}_{7}$ products in the pyrolysis of $o$-xylene at 0.04 and 1 atm.

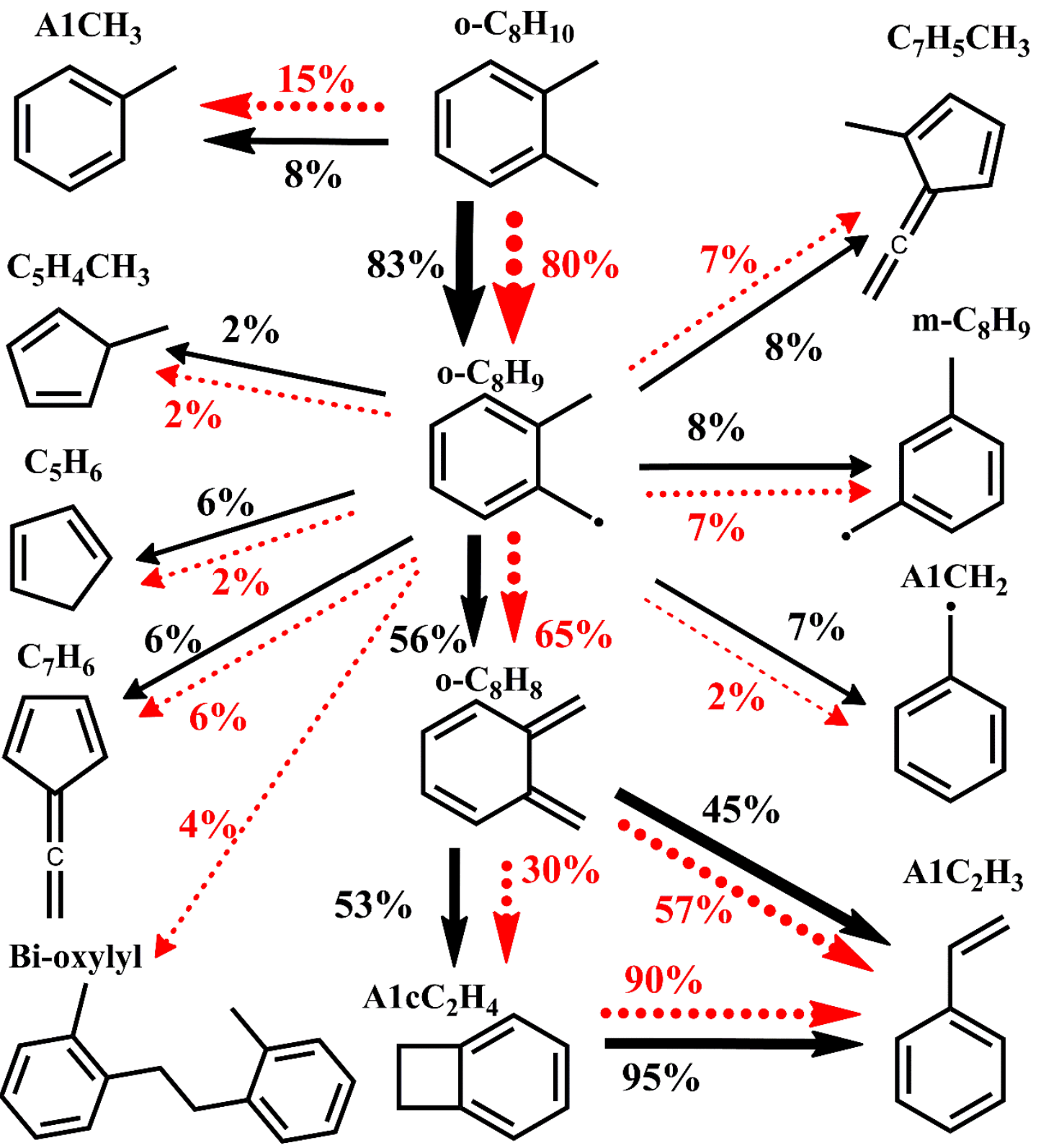

Fig. 3 Main reaction network of the fuel decomposition in the pyrolysis of $o$-xylene. Black solid and red dotted arrows denote pathways at 0.04 and 1 atm, respectively, together with their contributions (numbers with corresponding colors). 


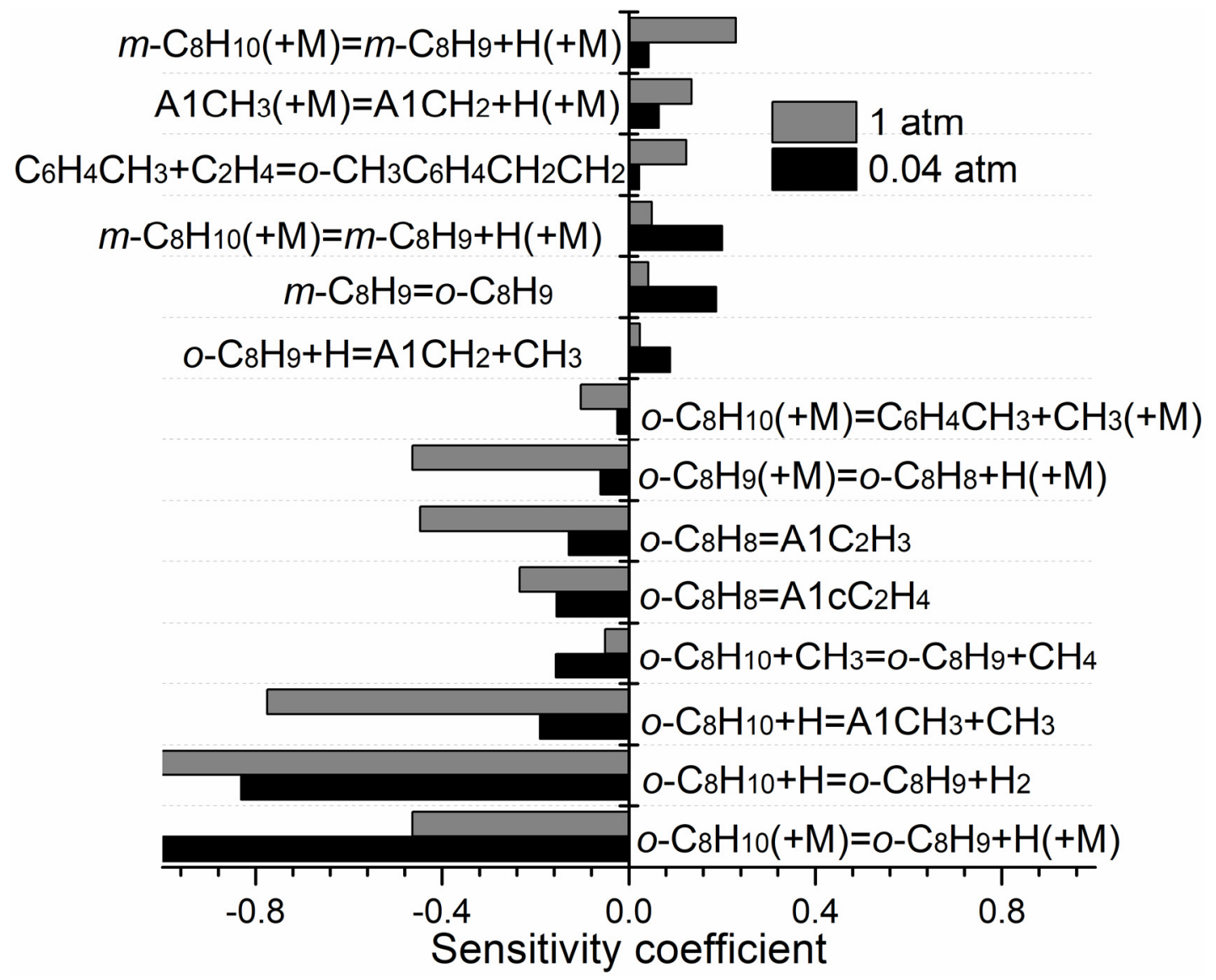

Fig. 4 Sensitivity analysis of $o$-xylene in the pyrolysis of $o$-xylene at 0.04 and $1 \mathrm{~atm}$. Top 14 reactions that promote/inhibit the decomposition reactivity of $o$-xylene are listed.
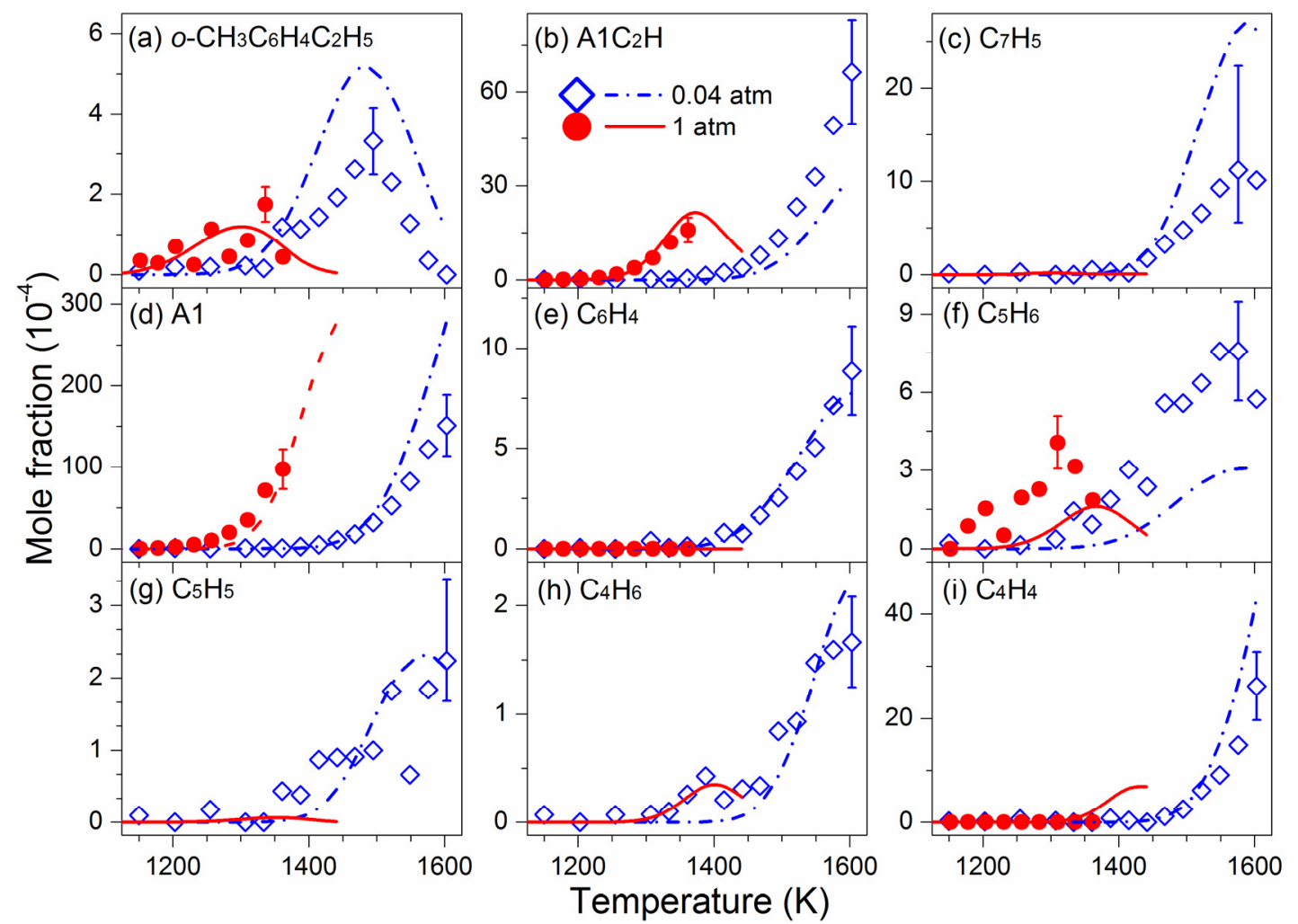

Fig. 5 Experimental (symbols) and simulated (lines) mole fraction profiles of several $\mathrm{C}_{9}-\mathrm{C}_{4}$ products in the pyrolysis of $o$-xylene at 0.04 and $1 \mathrm{~atm}$. 


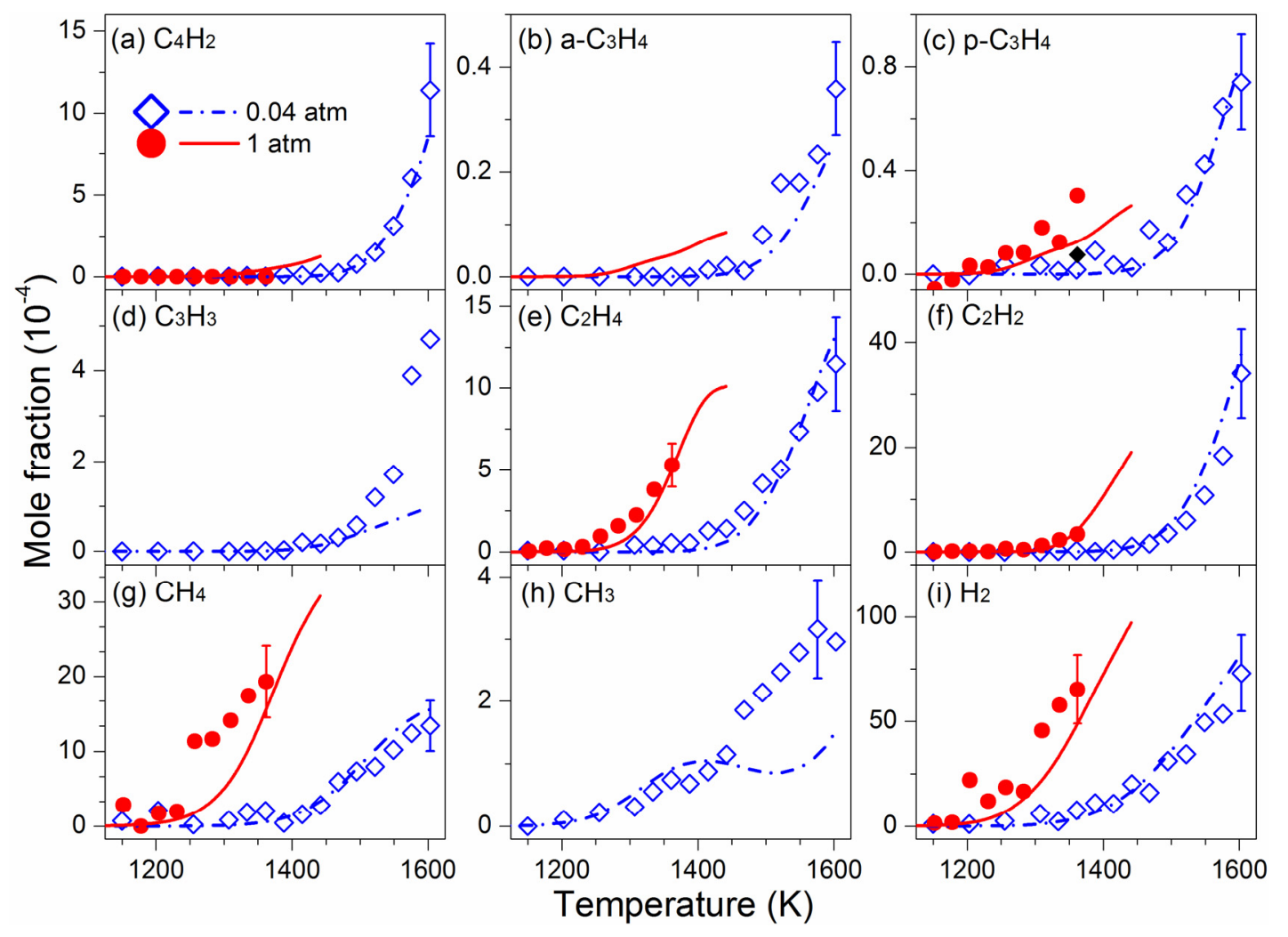

Fig. 6 Experimental (symbols) and simulated (lines) mole fraction profiles of $\mathrm{C}_{4}-\mathrm{C}_{0}$ products in the pyrolysis of $o$-xylene at 0.04 and $1 \mathrm{~atm}$.
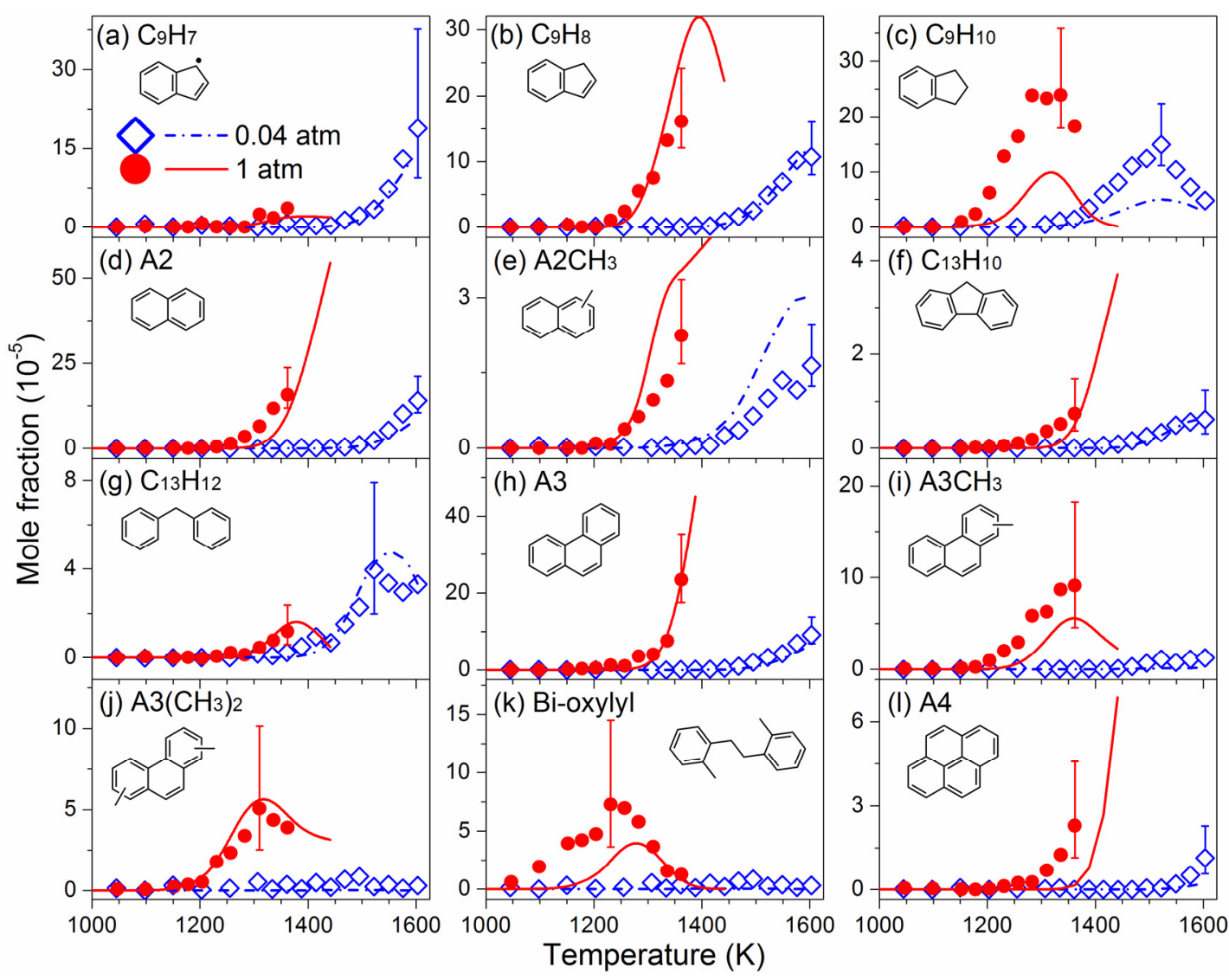

Fig. 7 Experimental (symbols) and simulated (lines) mole fraction profiles of PAHs in the pyrolysis of $o$-xylene at 0.04 and $1 \mathrm{~atm}$. 


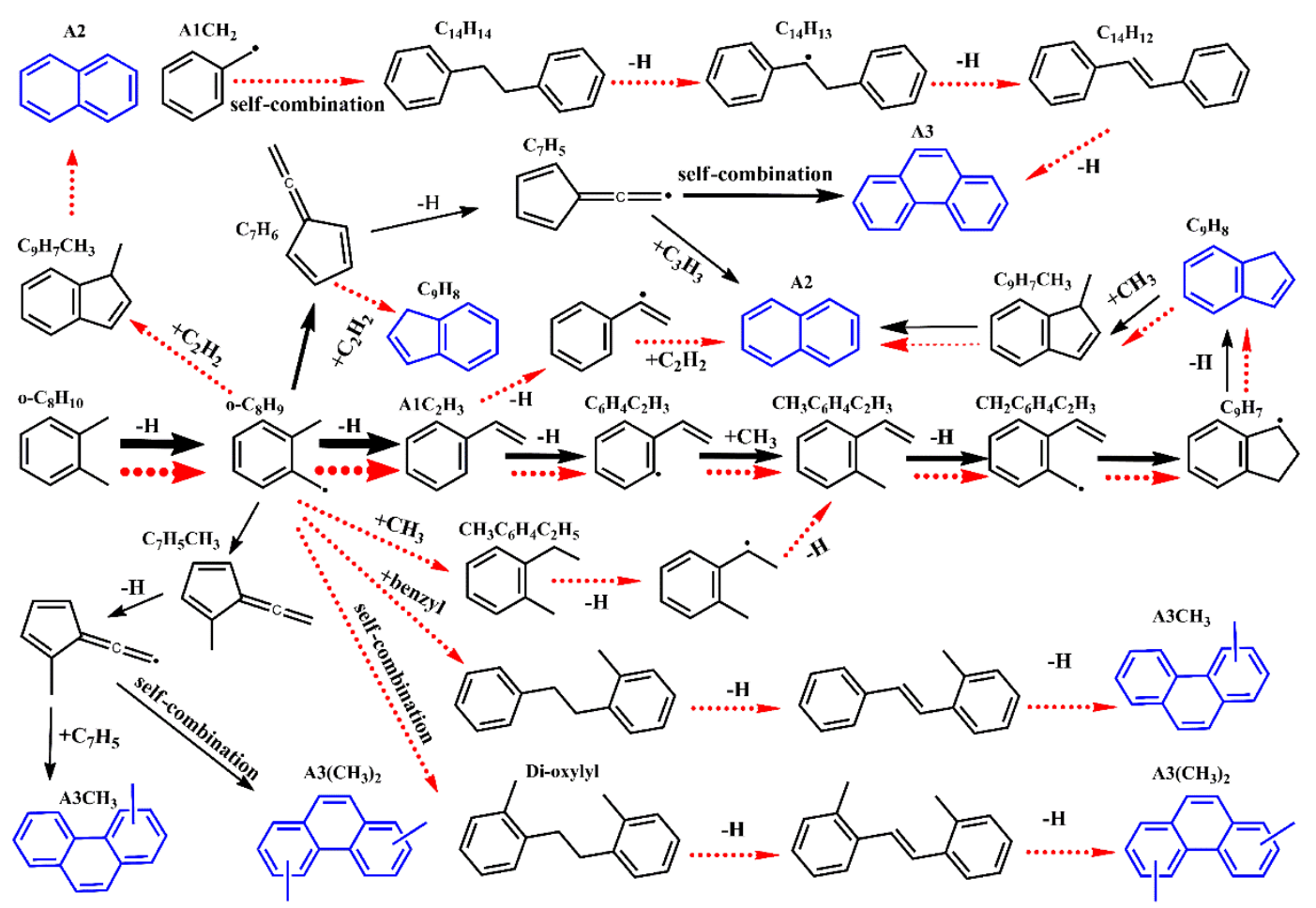

Fig. 8 Main reaction network of PAH formation in the pyrolysis of $o$-xylene. Black solid and red dotted arrows denote pathways at 0.04 and $1 \mathrm{~atm}$, respectively. The PAHs observed in this work are highlighted in blue color.

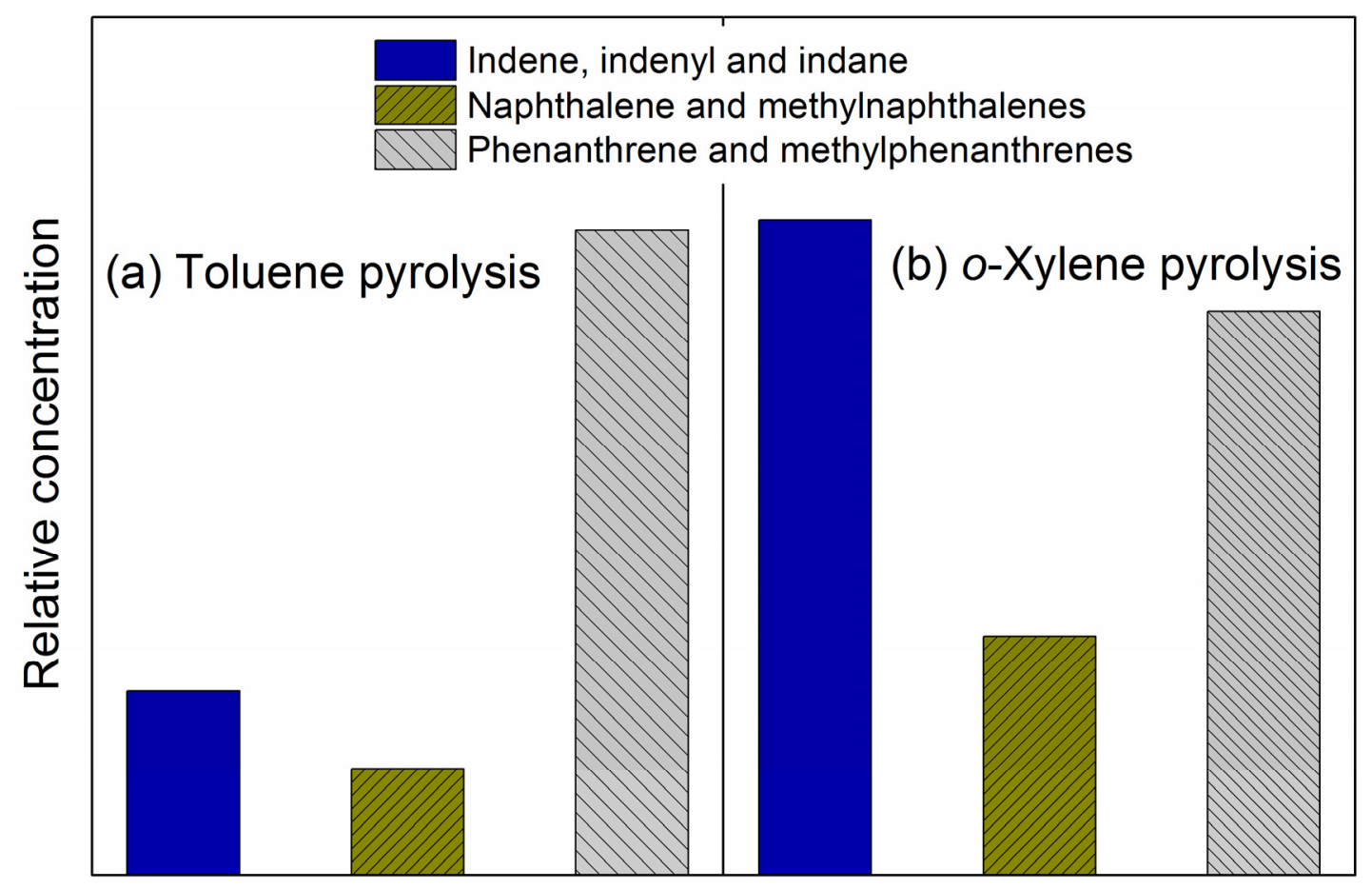

Fig. 9 Comparison of the relative concentration of three kind of PAHs produced in the pyrolysis of toluene and $o$-xylene. 


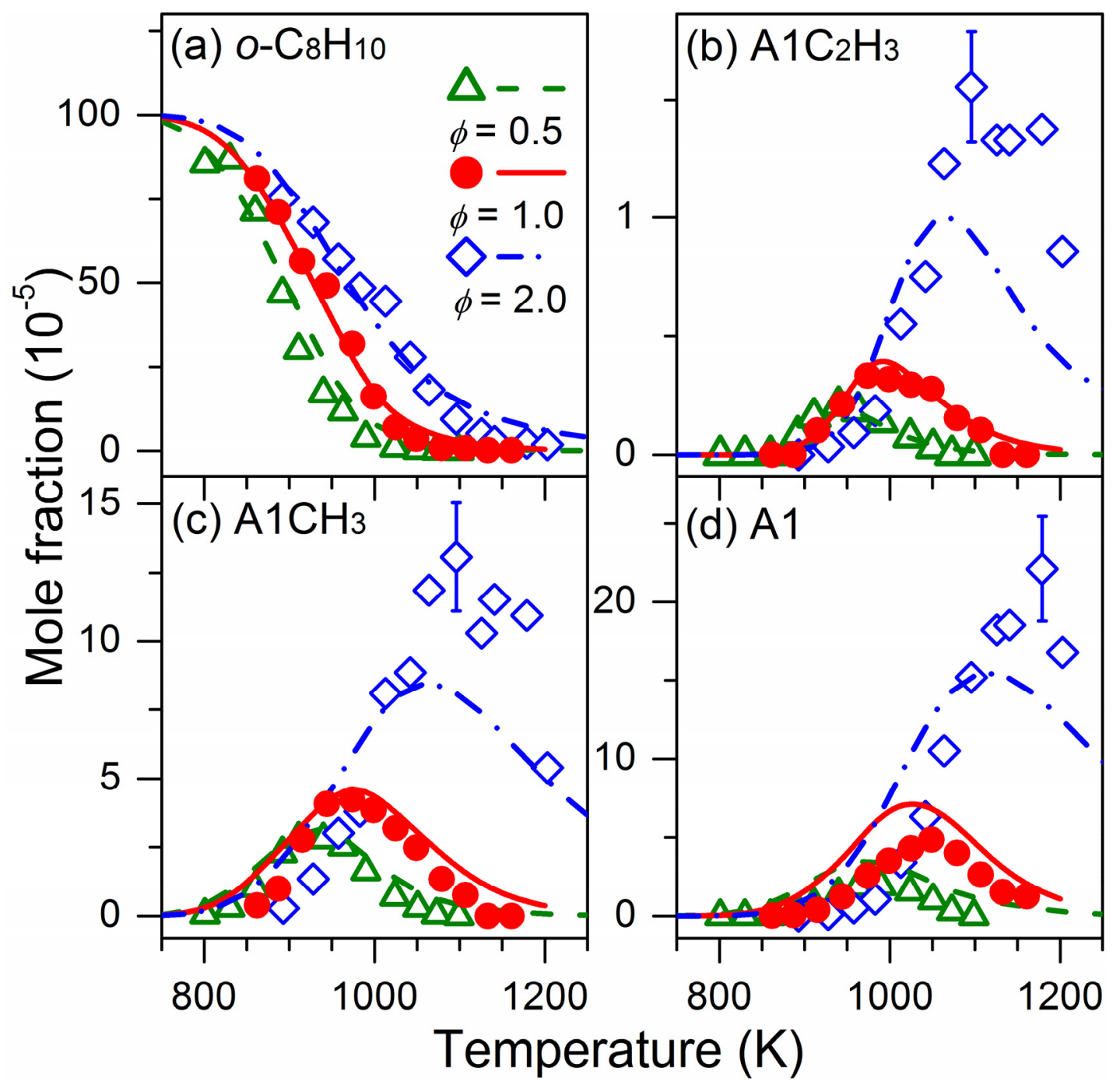

Fig. 10 Experimental (symbols) and simulated (lines) mole fraction profiles of $o$-xylene and major aromatic products in the JSR oxidation of $o$-xylene at $10 \mathrm{~atm}, \tau=0.5 \mathrm{~s}$ and $\phi=0.5,1.0$ and 2.0 . 


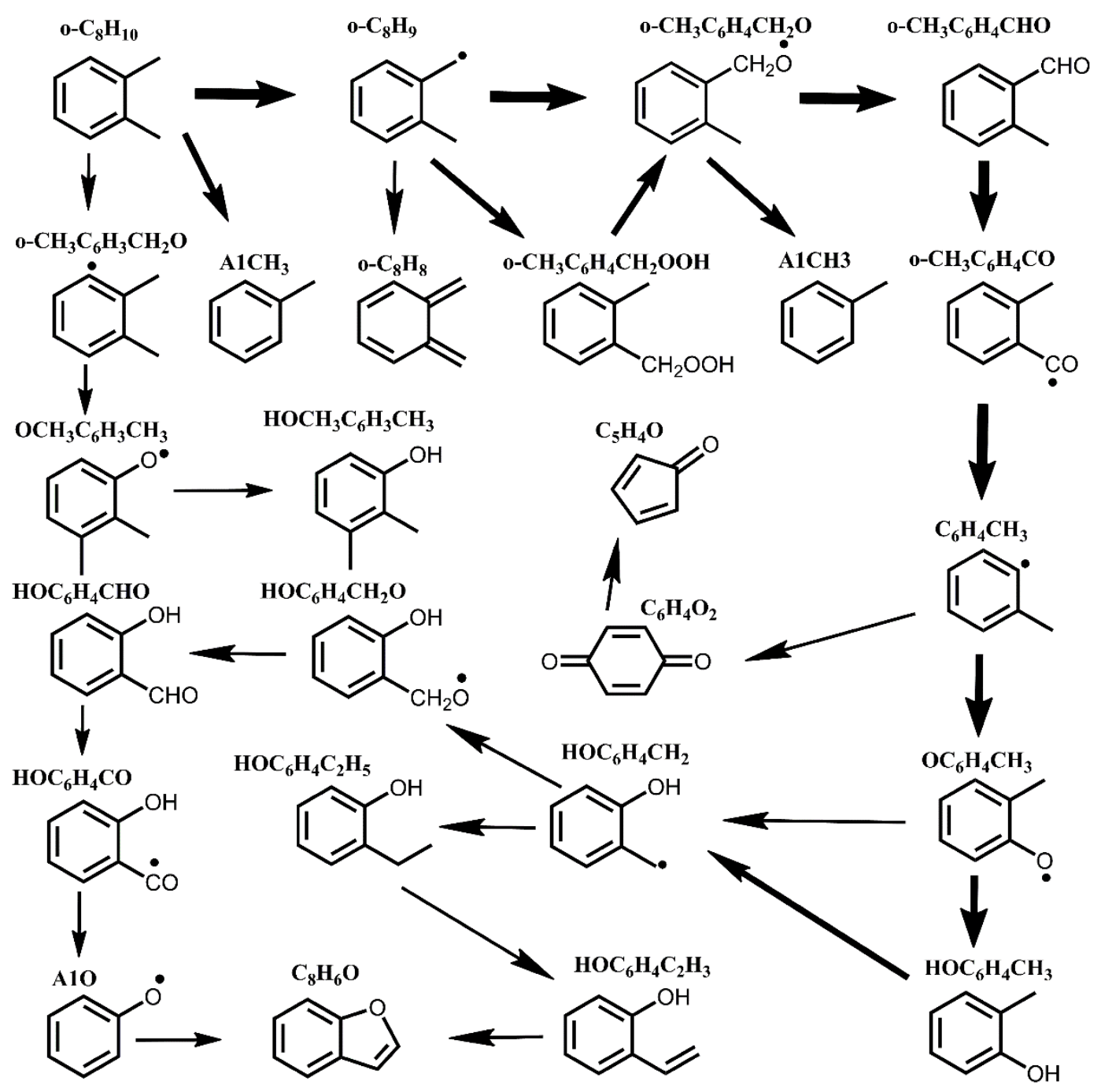

Fig. 11 Main reaction network in the JSR oxidation of $o$-xylene at $10 \mathrm{~atm}(\phi=1.0,975 \mathrm{~K})$.

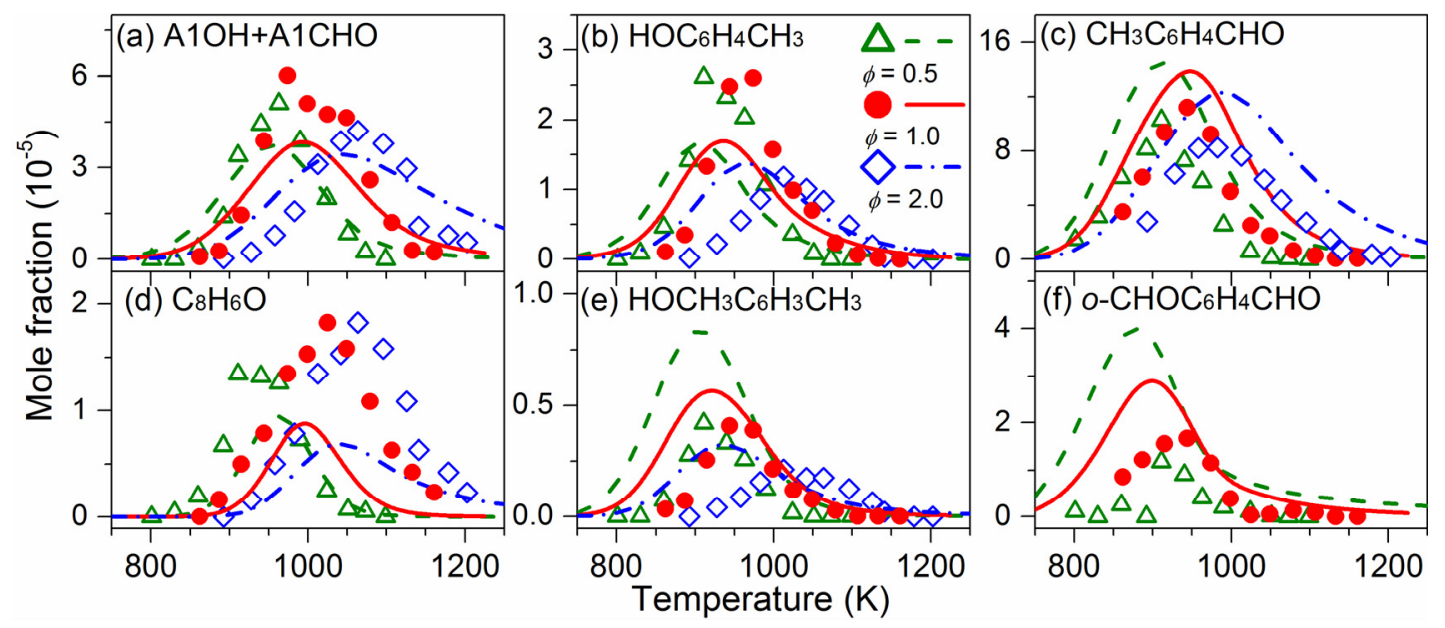

Fig. 12 Experimental (symbols) and simulated (lines) mole fraction profiles of major oxygenated products in the JSR oxidation of $o$-xylene at $10 \mathrm{~atm}, \tau=0.5 \mathrm{~s}$ and $\phi=0.5,1.0$ and 2.0. 

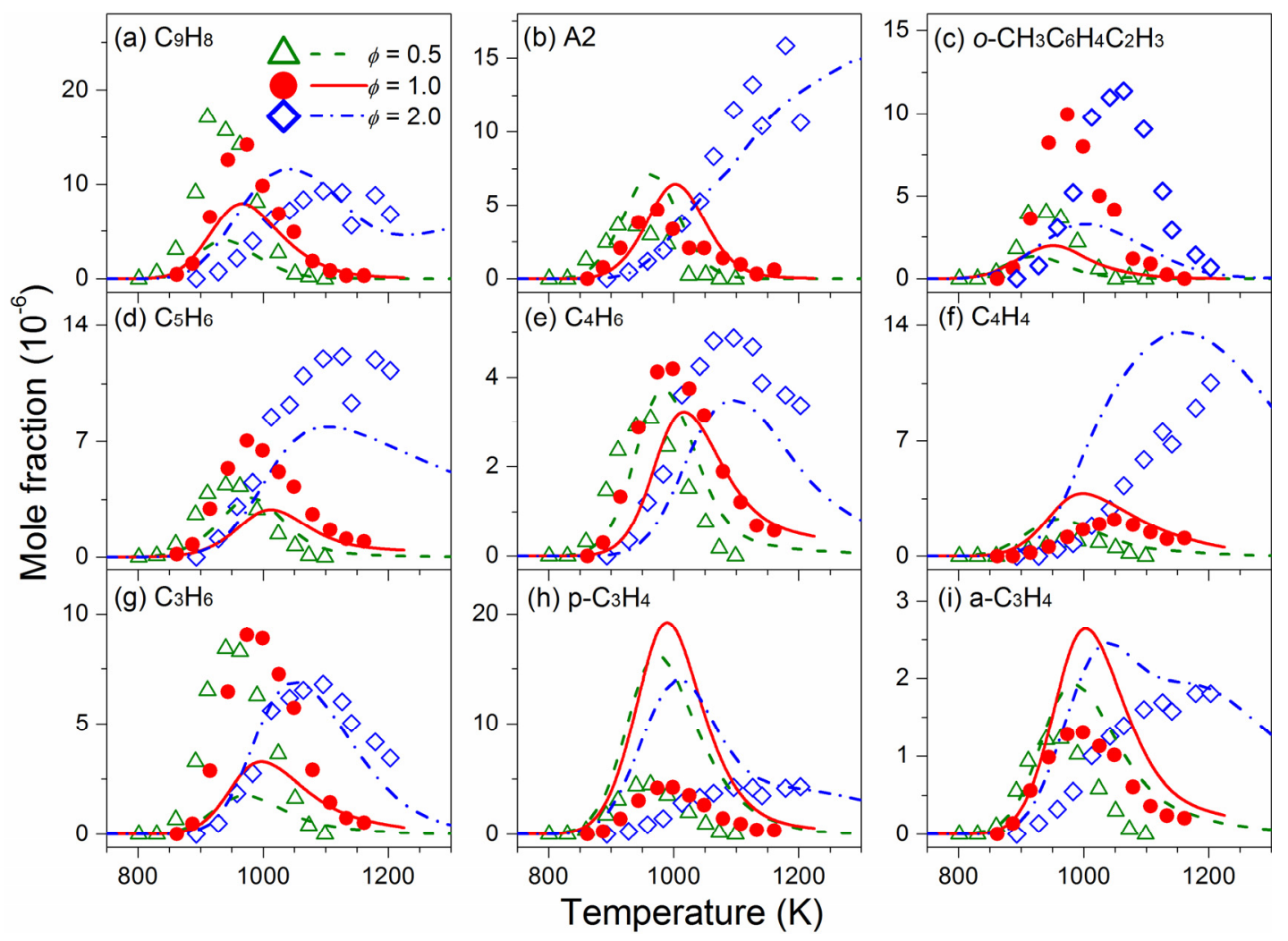

Fig. $\quad 13$

Experimental (symbols) and simulated (lines) mole fraction profiles of indene, naphthalene, $o$-methylstyrene and $\mathrm{C}_{5}-\mathrm{C}_{3}$ products in the JSR oxidation of $o$-xylene at $10 \mathrm{~atm}, \tau=0.5 \mathrm{~s}$ and $\phi=0.5,1.0$ and 2.0 .
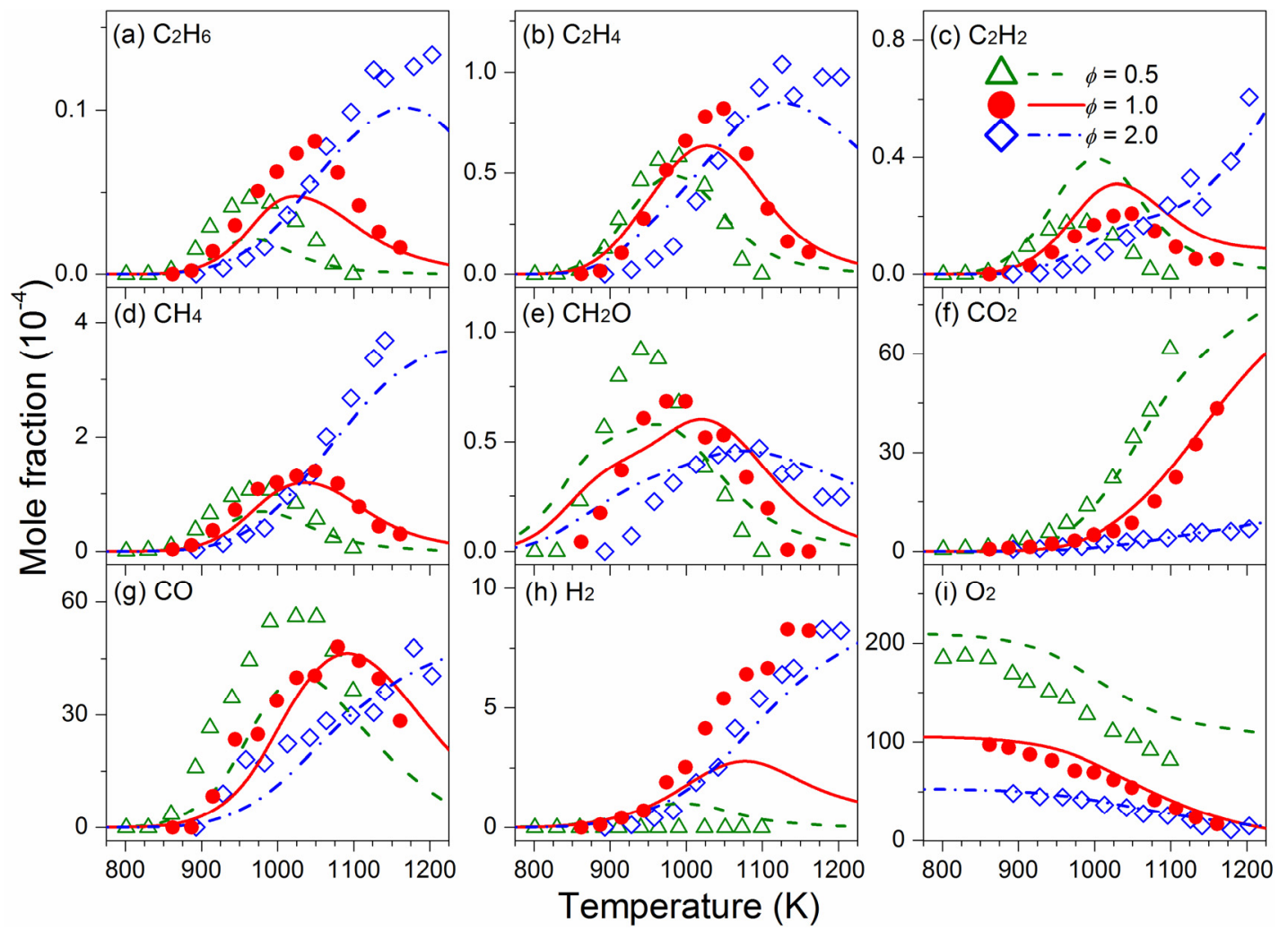

Fig. 14 Experimental (symbols) and simulated (lines) mole fraction profiles of $\mathrm{C}_{2}-\mathrm{C}_{0}$ products and $\mathrm{O}_{2}$ in the JSR oxidation of $o$-xylene at $10 \mathrm{~atm}, \tau=0.5 \mathrm{~s}$ and $\phi=0.5,1.0$ and 2.0. 